\title{
ANÁLISE DA BIBLIOGRAFIA SOBRE PESCADORES, COLETORES E CAÇADORES QUE OCUPARAM O ESTADO DO RIO DE JANEIRO*
}

Maria Dulce Gaspar**

\section{Introdução}

Este artigo tem como principal objetivo analisar os esquemas explicativos que tratam do processo de ocupação dos pescadores, coletores e caçadores na área compreendida pelo estado do Rio de Janeiro. Pretende ser uma releitura dos dados disponíveis e uma contextualização das interpretações mais difundidas, não se propondo a realizar um exame crítico da produção científica, mas a proceder a uma análise que busca entender o processo de construção dos esquemas referidos e avaliar a sua eficácia.

Cabe ressaltar que as obras apreciadas não se restringem aos temas aqui tratados, abarcando, sem dúvida, um universo bem mais complexo do que o sintetizado no presente estudo. E mais: ainda que não considere o recorte espacial proposto o estado do Rio de Janeiro apropriado para levar a termo uma reflexão sobre pré-história, trata-se de uma contingência imposta pela própria investigação, que visa a sistematizar informações bibliográficas de autores cuja maioria tem essa divisão política como referência.

A pré-história do Rio de Janeiro já foi tema de vários estudos em períodos anteriores

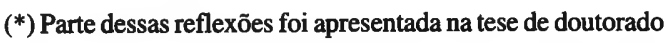
intitulada "Aspectos da organização de um grupo de pescadores, coletores e caçadores: região compreendida entre a ilha Grande e o delta do Paraíba do Sul", defendida pela autora na USP. Muitos dados foram extraídos da pesquisa relacionada com os projetos " $\mathrm{O}$ aproveitameto ambiental das populações pré-históricas do estado do Rio de Janeiro", convênio FINEP/ FUJB/MN, e "Estudo e cadastro dos testemunhos pré-históricos dos pescadores, coletores e caçadores ribeirinhos e costeiros", financiado pelo CNPq.

(**) Museu Nacional da Universidade Federal do Rio de Janeiro.
(Backheuser 1919; Mezzalira 1946; e Guerra 1955), porém, serão focalizados apenas os trabalhos que integram o que Prous (1991: 14) denominou de "período recente", caracterizando o momento em que surgiram os grandes projetos de pesquisa arqueológica. As investigações da década ainda em curso serão apreciadas apenas como tendências, pois só com o desdobramento dos estudos e os efetivos avanços poder-se-á fazer uma avaliação crítica de suas contribuições.

No que se refere ao período compreendido por esta análise, deve-se ressaltar o papel precursor de Ondemar Dias Jr., que foi o primeiro a enfocar questões especificamente arqueológicas, tendo os trabalhos desenvolvidos sob sua coordenação marcado o início da pesquisa científica no estado do Rio de Janeiro. Também importantes são as pesquisas coordenadas por Alfredo Mendonça de Souza e Sheila Mendonça de Souza, Maria da Conceição Beltrão, Lina Maria Kneip e Osvaldo Heredia, das quais se extraiu a maioria das informações que permitiram o desenvolvimento desta reflexão.

No conjunto da bibliografia, foi constatada a presença de duas tendências de pesquisa: a primeira centrada no estudo de sítios isolados, e a segunda voltada para estabelecer quadros gerais da ocupação do estado. A análise da produção bibliográfica indica que as duas linhas são articuladas e complementares, e que a maioria dos autores apresenta contribuições em ambas as vertentes. Trata-se, na realidade, de um sistema circular, no qual um esquema alimenta-se de informações advindas do outro, e este, por sua vez, busca explicações e interpretações no primeiro.

Serão apresentadas, de início, as pesquisas que estudam sítios como unidades isoladas e, posteriormente, a tendência relativa à perspectiva generalizante. 


\section{Estudos particularistas}

As pesquisas que se desenvolvem em torno de um sítio específico podem-se agrupar em três modalidades:

1) aquelas que apresentam acentuada influência francesa, sobretudo de Leroi-Gourhan, e cuja ênfase especial é dada ao estudo da composição espacial do sítio, da distribuição interna dos vestígios arqueológicos e das atividades que as originaram (Kneip 1976). Segundo essa perspectiva analítica, "estrutura" é a noção crucial que sustenta a interligação dos eventos e perpassa toda a prática de campo apoiada na identificação e correlação dos testemunhos arqueológicos. Os procedimentos técnicos corroboram, assim, a abordagem do sítio enquanto unidade de análise por excelência e têm a sua expressão máxima na técnica de decapagem que é utilizada como forma de evidenciar a posição dos vestígios no contexto geral (Pallestrini apud Kneip,1977: 33). O recorte espacial é dado pelas dimensões do próprio sítio, uma característica a mais dessa modalidade de concepção arqueológica.

Lina Kneip é a pesquisadora que melhor representa essa vertente de trabalho e tem realizado o maior número de pesquisas (1976, 1977; Kneip, Pallestrini \& Cunha 1981; Kneip \& Pallestrini 1987; e Kneip, Crancio \& Rodrigues 1990), muito embora, o seu trabalho englobe uma diversidade de questões (adaptação ambiental, mudança cultural,... sempre apoiada no enfoque interdisciplinar. Recentemente, vem se dedicando a estudar em profundidade uma área específica do estado Saquarema e a estabelecer correlações entre vários sítios, enfocando subsistência, rito funerário e moradia, entre outros temas (Kneip, Pallestrini, Crancio \& Machado 1991; Kneip 1992; Kneip \& Machado 1993; Kneip 1994; e Kneip \& Machado 1994). O trabalho de Eliana Carvalho (1984) também pode ser incluído na mesma modalidade.

2) as pesquisas que revelam uma influência significativa da arqueologia americana, em especial da Ecologia Cultural. Entre os projetos mais representativos dessa vertente, destaca-se o de Osvaldo Heredia (1978, 1983, 1984, 1985, 1986 e 1987), cujo objetivo é a realização de sondagens, através de níveis artificiais, em um grande número de sítios do litoral, a fim de obter uma visão abrangente da ocupação pré-cerâmica. A pesquisa tem como prioridade estabelecer a natureza das relações entre sítio e meio, efetuando uma análise detalhada dos distintos ambientes explorados pelos habitantes pré-históricos, bem como a caracterizar a cultura estudada, mediante a descrição minuciosa dos recursos disponíveis e daqueles efetivamente explorados. Em todos os trabalhos desenvolvidos pela equipe (Heredia, Beltrão, Gaspar \& Gatti 1981/82; Heredia, Gaspar, Gatti \& Franco 1983; Heredia, Gatti, Gaspar \& Buarque 1994; Heredia, Gaspar, Scaramella \& Franco 1985; Heredia, Gaspar, Sette \& Bulcão 1985; e Heredia, Tenório, Buarque \& Gaspar 1985), porém, os sítios são tratados isoladamente.

A investigação realizada por Alfredo e Sheila Mendonça de Souza (1983) no sambaqui do Rio das Pedrinhas também pode ser incluída na mesma modalidade de pesquisa.

3) as pesquisas que apresentam contribuições específicas, quer na área de estudo de restos faunísticos (Kneip, Coelho, Cunha \& Mello 1975; Mendonça de Souza, Santos, Schramm \& Miranda 1983/84; Lima \& Silva 1984: 10-40; Azevedo, Carvalho \& Dias 1981/82: 157-160; e Lima 1991), quer no estudo morfométrico dos seixos (Kneip et alii 1990), de alguns aspectos da tecnologia (Pallestrini \& Chiara 1981: 71-94; e Lima, Mello \& Silva 1986), da ordenação espacial (Barbosa, Gaspar \& Barbosa 1994), da representatividade da amostragem (Gaspar, Barbosa \& Barbosa 1994) e do uso de informática na interpretação de sítios (Tenório 1995). Embora pontuais, esses trabalhos têm fornecido resultados relevantes quanto ao próprio tema a que se propõem e propiciado a incorporação e avaliação de novas técnicas e estratégias de investigação.

Outra linha de pesquisa, ainda incipiente, vem se delineando sob minha coordenação e constitui, em certo sentido, um desdobramento dos trabalhos de Osvaldo Heredia, com clara inspiração nos estudos de Michel Schiffer (1991) e marcada influência da Escola Sociológica Francesa, sobretudo de Marcel Mauss (1974). É com base nessa perspectiva que proponho uma ordenação distinta dos esquemas ora em análise (Gaspar 1991, 1994/95, 1995, no prelo a, b; Gaspar, Barbosa \& Barbosa 1994, Barbosa \& Gaspar, no prelo). 


\section{Esquemas gerais}

$O$ esquema mais abrangente e coerente que ordena os dados referentes à pré-história do Rio de Janeiro é o sistema de fases e tradições, amplamente divulgado no Brasil em decorrência dos trabalhos do Programa Nacional de Pesquisa Arqueológica (Pronapa), conduzido de 1969 a 1970, e do Programa Nacional de Pesquisa na Bacia Amazônica (Pronapaba), iniciado em 1977 (Meggers \& Evans 1985: 5).

A linha de pesquisa adotada por esses programas mantém estreita relação com os princípios abraçados pela Ecologia Cultural, escola que postula a explicação dos fatos sociais a partir de dados ecológicos (Panoff \& Perrin 1973: 88, 102-104) e considera a cultura como parte constituinte do ecossistema, no seio do qual o homem é tratado como uma espécie natural. Os fenômenos relacionados à mudança cultural são percebidos, compreensivelmente, pela ótica do neo-evolucionismo.

Meggers e Evans são os principais responsáveis pela divulgação dessa perspectiva de conhecimento, estruturada a partir de uma noção organicista de cultura que considera os fenômenos culturais semelhantes aos orgânicos (1970: 9), com pressupostos metodológicos baseados em analogias com a biologia, em especial no que se refere ao método taxonômico (1970: 6-9).

A pesquisa por eles desenvolvida tem como principal objetivo estabelecer fases e tradições, utilizando como instrumento analítico a seriação Ford (1970 e 1985), procedimento que ordena os vestígios a partir de tipologias e é concebido para detectar mudanças através do tempo e no espaço. Para Meggers e Evans (1985: 18), "uma tradição compreende um número variável de fases que compartilham um conjunto de atributos na cerâmica, artefatos líticos, padrões de assentamento, subsistência, ritual e demais aspectos da cultura". Tradição e fase mantêm a mesma relação que o gênero biológico possui com a espécie, tendendo a primeira a persistir por mais tempo e a ocupar áreas mais extensas. A fase, por sua vez, é definida segundo uma seqüência seriada e representa a expressão arqueológica de uma comunidade etnográfica (1985: 19).

É da estreita relação proposta por esses autores entre antropologia, em particular a arqueologia, e biologia, especialmente a de Simpson (apud Meggers e Evans 1970: 2-5), que se estrutura o princí- pio teórico norteador dessà linha de trabalho a proeminência dos fenômenos ambientais sobre os culturais.

O precursor dessa corrente no estado do Rio de Janeiro é Ondemar Dias Jr., e os resultados de seus trabalhos constituem referência obrigatória para todos os pesquisadores, mesmo aqueles que discordam de determinados pontos. Eliana Carvalho e Lilia Machado, em diferentes oportunidades, vêm se empenhando na sua divulgação e, ao lado de Ondemar Dias e de outros pesquisadores, têm orientado as pesquisas realizadas pelo Instituto de Arqueologia Brasileira (IAB).

A produção de Alfredo e Sheila Mendonça de Souza, na época responsáveis pelo Instituto Superior de Cultura Brasileira (ISCB), pode igualmente ser inserida nessa linha de pesquisa, tendo seus trabalhos contribuído para um desdobramento do quadro proposto pela equipe do IAB. A pesquisa de Tania Andrade Lima (1991), ainda que voltada prioritariamente para a zooarqueologia, também faz referência ao mesmo esquema interpretativo.

Outras ordenações dos vestígios arqueológicos fluminenses foram propostas pelas diferentes equipes do Museu Nacional, coordenadas por Maria da Conceição Beltrão, Lina Kneip e Osvaldo Heredia, porém seus esquemas não tiveram a mesma repercussão que $o$ anterior.

\section{Quadro proposto \\ pelos pesquisadores do IAB}

De acordo com Ondemar Dias (1987: 57), o início da ocupação do litoral fluminense se deu há cerca de 8.000 anos por coletores de moluscos, cujos restos teriam formado os sítios denominados sambaqui, agrupados na fase Macaé (1969) e construídos, segundo as datações disponíveis, por volta de 7803 土 130 AP (datação de Maratuá) até 3975 \pm 160 AP (sambaqui do Ury).

Pertencem a essa fase, além das duas ocupações iniciais do sambaqui do Forte (Dias, 1978/ 79/80: 41), dez sambaquis, dos quais apenas o Ury e o Tambor foram nomeados por Ondemar Dias (1969: 145-146), enquanto Alfredo Mendonça de Souza (1981: 40), citando comunicação pessoal daquele autor, apresentou os oito restantes: Aroeira de São Jorge e Marimbondos, em Macaé; Tarioba e Vila Nova, em Casimiro de Abreu; Campo da Boa Vista e Marrecas, em São João da Barra; e São João e Entulho, em Cabo Frio. 
Embora Ondemar Dias não tenha estabelecido os limites espaciais da fase Macaé, é possível pressupor que abrangesse, além do litoral do Rio de Janeiro, o de São Paulo, em cujo território são identificados com a mesma fase os sítios de Piaçaguera e Mar Casado. As informações disponíveis sobre a localização dos sítios que a integram indicam que estão assentados a uma distância variada da costa, porém, em quase todos os casos, a pouca altura acima do nível do mar (Dias 1969: 145).

Em publicação sem data, o autor propõe uma subdivisão dos sambaquis que compõem a fase Macaé em dois grupos: os mais antigos e os mais recentes. Os primeiros caracterizar-se-iam por contar com maior quantidade de conchas, e os segundos, pela presença de espessas camadas húmicas. Alterações ambientais, sobretudo aquelas relacionadas com os movimentos do nível marinho, teriam tornado difícil a manutenção da dieta alimentar baseada exclusivamente nos moluscos aquáticos, o que levou a uma diversificação na economia, dando origem à tradição Itaipu (Dias 1987: 157).

Tradição Itaipu é denominação utilizada para identificar os sítios que atestam a adaptação às mudanças climáticas. Subdivide-se em duas fases, A e B. Pertencem à fase $\mathrm{A}$ os sítios registrados como sambaquis por Salles Cunha (1965) - Piraquê, Poço das Pedras, Porto das Cinzas, Ilha do Tatu, Zé Espinho, Pau-Ferro, Aterrado da Praia, Telégrafo, Vila Mar, Posto 5, Curral das Pedras, Matriz, Teles, Piteiras ou do Anil, Panela do Pai João, Gentio, Atolador, Praia do Malhador, Cerâmio, Benta, Sucuruí, Vaso, Piracão, Meio, Cabeça de Índio 1 e 2, Barreira, Araçatiba ou Campo de São João, Porto das Pitangueiras, Porto do Teixeira e Piaí -, ainda que Ondemar Dias não os nomeie (1976/77: 116), e os sítios Corondó e Malhada (Dias \& Carvalho 1983/84: 98). À fase B estão vinculados o sítio Itaipu (Dias 1978/79/80: 35), a última ocupação do Forte (Dias \& Carvalho 1983/ 84: 98) e ainda as dunas de Bela Vista, Grande de Itaipu e Pequena de Itaipu, bem como os sítios da Praia Grande, de Massambaba e de Jandira e a Illha de Santana (Dias 1988).

A dieta alimentar da fase A caracteriza-se pelo consumo de vegetais e moluscos, complementada pela caça de pequenos animais, crustáceos e pesca, enquanto na fase B parece ter havido um incremento da pesca, embora a coleta de moluscos seja comum (Dias 1976/77: 116). A alimentação dos grupos relacionados com a tradição Itaipu é comple- mentada pela coleta de sementes e pela agricultura incipiente.

Segundo Ondemar Dias (1976/77: 116), os sítios identificados com a fase A estão localizados em áreas mais interioranas, à beira de mangues, em lagoas de águas paradas ou de pouco movimento. Os sítios da fase B situam-se sobre dunas estáveis, algumas de dimensões consideráveis, em longas praias de mar aberto, preferencialmente no seu final, onde se observa uma curvatura mais acentuada do litoral e a arrebentação é menos violenta, sendo considerado fator importante o ponto em que se dá a ligação da lagoa com o mar.

No tocante à composição dos sítios, alguns registram a presença de cerâmica nos últimos níveis de ocupação, sem que ocorram alterações nos demais elementos. Os sítios da fase Itaipu A apresentam estruturas bem definidas - alimentares (áreas de concentração de restos de moluscos ou peixes), habitacionais (áreas delimitadas com estacas e que apresentam piso de silt) e cerimoniais (sepultamentos simples ou múltiplos). Já os sítios da fase B contam apenas com dois tipos de estruturas - alimentares e cerimoniais, essas últimas muito raras (Dias 1988: 171).

Quanto aos limites espaciais, a tradição abrangeria o litoral do Espírito Santo, ocorreria também no Rio Grande do Sul, compondo a subtradição Apicum (Dias 1975: 8, 1976/77: 116; e Carvalho 1990: 120). Estudos posteriores realizados por Schmitz indicaram, todavia, que os sítios do Sul correspondem a acampamentos costeiros de grupos procedentes do interior, não se justificando, portanto, sua filiação à tradição (Dias 1988: 162).

Na proposição dos pesquisadores do IAB, os grupos identificados com a tradição Itaipu são os herdeiros dos grupos relacionados com os sambaquis (Dias, 1976/77: 42 e Dias \& Carvalho, 1983/84: 100), com adaptações derivadas de mudanças climáticas. $O$ estudo dos esqueletos não aponta diferenças marcantes entre as três fases Macaé, Itaipu A e Itaipu B - quanto à conformação genética, resumindo-se as variações aos aspectos culturais (Dias \& Carvalho 1983/84: 100).

Como ocorre em toda pesquisa, o esquema inicial sofreu alterações, com a incorporação de novos dados. Os primeiros trabalhos de Ondemar Dias (1969: 146) informavam que a análise dos restos assinalava diferenças entre as fases Macaé, Itaipu A e Itaipu B devido ao incremento da pesca em detrimento da coleta, transformação esta de- 
corrente de mudanças ambientais. A partir do artigo de 1975, o sistema evoluiu e fixou-se na discussão sobre a presença de agricultura, passando a intensificação da pesca para segundo plano.

A proposição original também se modificou no tocante às atividades agrícolas como características da fase Itaipu B (Dias 1978/79/80: 34), sendo o surgimento da agricultura antecipado para a fase Itaipu A. A nova interpretação parece ter se apoiado nos resultados dos trabalhos desenvolvidos no sítio Corondó, vinculado à fase $\mathrm{A}, \mathrm{e}$, particularmente, nos estudos de antropologia física realizados por Lilia Machado (Turner \& Machado 1981/82 e Machado 1988).

Seguindo o esquema proposto pelos pesquisadores do IAB, o estado do Rio de Janeiro passou a ser ocupado por grupos ceramistas identificados com a tradição Una, que constitui a mais antiga manifestação de grupos horticultores e ceramistas. Ocorre no Rio de Janeiro (Dias \& Carvalho 1980) e ainda no sudoeste de Goiás (Schmitz et alii, 1982: 264), oeste de Minas Gerais (Dias 1976/77: 110130), interior de São Paulo (Dias 1976/77: 125) e Espírito Santo (Perota 1969: 70).

No Rio de Janeiro, a tradição Una foi subdividida nas fases Mucuri e Una (Dias 1976/77: 117). A fase Mucuri, localizada no norte do estado, no baixo e médio Paraíba e na região serrana, está datada de $1430 \pm 65 \mathrm{AP}(520 \mathrm{dC})$ e atinge até $720 \pm$ $95 \mathrm{AP}(1230 \mathrm{dC})$. A fase Una, datada em $1060 \pm 90$ AP $(890 \mathrm{dC})$, é litorânea, e dela são encontradas evidências arqueológicas em Cabo Frio. Estudos recentes estão sendo desenvolvidos no sítio do Caju, no baixo Paraíba do Sul, datado de $1453 \pm 65 \mathrm{AP} \mathrm{e}$ $850 \pm 90 \mathrm{AP}$ e caracterizado como da fase Mucuri, já se encontrando disponíveis informações relacionadas com os sepultamentos (Machado 1994).

No litoral, não foram estudados sítios semelhantes aos da região serrana, como os abrigos ou sítios em campo aberto. Os vestígios para os quais se dispõe de informações mais consistentes parecem estar em sítios costeiros da tradição Itaipu. Nos sambaquis da Pontinha e do Moa, em Saquarema, foi encontrada cerâmica, considerada filiada à fase Una (Crancio \& Kneip 1992) e datada em $3610 \pm 190$ AP (Kneip, Ferreira \& Muehe 1994: 129) - esta datação confere uma antigüidade inesperada para a cerâmica no litoral fluminense. Infelizmente, são escassas as informações sobre a fase correspondente à área povoada pelos pescadores, coletores e caçadores.
Em momento posterior, algumas áreas do estado do Rio de Janeiro foram ocupadas por outros grupos, sendo seus testemunhos denominados de tradição Tupiguarani. A essa tradição corresponderia um sistema de adaptação diverso do da tradição Una, tendo seus grupos se mantido próximos dos rios, valendo-se de enterramentos secundários em urnas e não estando associados a sítios cobertos (Dias 1976/77 e Dias \& Carvalho 1980).

A tradição Tupiguarani foi dividida em cinco fases: Guaratiba, litorânea, na costa central do estado, em sítios da tradição Itaipu, datada de $970 \pm$ 100 AP; Sernambitiba, litorânea, também na costa central, porém mais para o norte; Itabapoana, litorânea, ao norte, após a foz do Paraíba, com ocorrência também no Espírito Santo; Itaocara, no interior, no médio curso do rio Paraíba, a montante da área do rio Mucuri; e Ipuca, no médio curso do rio $\mathrm{Pa}$ raíba, alongando-se em direção à foz e atingindo boa parte do Mucuri.

Com a chegada dos europeus, instalou-se a tradição Neo-Brasileira, caracterizada pela presença de cerâmica tipicamente Tupiguarani, com intrusão de elementos europeus. A tradição foi dividida em duas fases: a Calundu, registrada em Cabo Frio, e a Parati, no litoral Sul, ocorrendo em sambaquis.

\section{Quadro proposto \\ pelos pesquisadores do ISCB}

Como já foi mencionado, o esquema elaborado por Alfredo e Sheila Mendonça de Souza baseiase no sistema estabelecido pelos pesquisadores do IAB. Na realidade, trata-se de um desdobramento do primeiro, com a criação de novas fases e o deslocamento temporal de algumas. Os elementos que o estruturam são também a composição e a localização dos sítios. Como na proposição anterior, um mesmo sítio pode se encaixar em duas fases distintas, situação recorrente explicada pelas alterações ambientais resultantes sobretudo das variações do nível do mar - classificação igualmente apoiada na curva de Fairbrigde. Tais variações, mais do que no esquema do IAB, são o elemento ordenador da proposta do ISCB, que busca estabelecer uma estreita relação entre as diferentes transgressões e regressões e as diferenças observadas na estratigrafia dos sítios. Como resultado dessa perspectiva, dá-se a subdivisão vertical dos sítios em pacotes estratigráficos, podendo um único sítio apresentar até mesmo quatro fases diferentes. 
Esse esquema também sofreu alterações devido à incorporação de novos dados. Segundo Alfredo Mendonça de Souza (1981: 73-79), o estado do Rio de Janeiro começou a ser ocupado há cerca de 10.000 anos por dois grupos distintos, cujos testemunhos, conforme assinalado em artigo posterior (Mendonça de Souza \& Mendonça de Souza 1981/ 82: 11), associam o primeiro com a tradição Itaipu, e o que o sucedeu, com a tradição Macaé.

Na proposição inicial, os primeiros ocupantes integrariam bandos provenientes de Minas Gerais, que se fixaram na região serrana no norte fluminense. Tinham sua economia baseada na caça e na recoleta, encontrando-se no estágio designado como Páleo-Índio Epigonal, ou talvez já no Arcaico Inferior. Com as mudanças ambientais, alguns grupos adaptaram-se aos novos habitats florestados, enquanto outros atingiram o litoral, dedicando-se à exploração de recursos marítimos e lacustres. $\mathrm{O}$ próprio Mendonça de Souza salienta, todavia, que a referência aos grupos do interior é hipotética e não se baseia em dados arqueológicos (1981: 74).

Tradição Macaé é o termo utilizado para denominar sítios que teriam sido ocupados por bando de coletores adaptados a recursos marinhos, oriundos provavelmente do Sul do Brasil (Mendonça de Souza 1981), tendo sido sua presença registrada em Parati, Magé e Cabo Frio. Os sítios característicos da tradição Macaé são conhecidos como sambaquis e incluem, em seu conjunto, a maioria daqueles considerados por Ondemar Dias como da fase Macaé, além da camada I do sambaqui do Forte e a maioria dos sambaquis estudados por Salles Cunha em Sepetiba e Guaratiba.

A economia dos grupos da fase Itaipu A é bastante diversificada, com predomínio da pesca e coleta de moluscos subsidiadas pela caça. Já a economia da tradição Macaé baseia-se na coleta de moluscos marinhos subsidiada pela pesca.

Há 4000 AP, todo o litoral fluminense estava ocupado pelas tradições Macaé, nesse momento representada pela subtradição Guapi, e a tradição

(1) Cabe ressaltar que um único sítio pré-cerâmico do interior foi descoberto por Ondemar Dias (1969: 122) e nele recuperadas pontas de projéteis foliáceas e pedunculadas feitas em quartzo (Dias \& Carvalho 1980: 56). Já são inúmeras as tentativas de localizar, no interior do estado do Rio de Janeiro, sítios deixados por caçadores (Heredia 1983 e 1984), porém o achado até agora de Ondemar Dias indica que a região não foi ocupada intensamente por grupos caçadores.
Itaipu, pela subfase Itaipu B. Em algumas áreas baía de Sepetiba e litoral central do estado -, os sítios das duas tradições localizam-se muito próximos uns dos outros, sendo provável que tenha havido contato. A subfase Itaipu B tinha a sua economia centrada na pesca e subsidiada pela coleta de moluscos, enquanto a subtradição Guapi baseavase na coleta generalizada subsidiada pela pesca (Mendonça de Souza 1981: 46).

A partir de 3000 AP, a subtradição Guapi começou a modificar-se gradualmente, até caracterizar a subtradição Macaé, registrada nos mesmos locais, com indústrias semelhantes e economia baseada na caça, pesca e coleta generalizada (Mendonça de Souza 1981: 46). Esta subtradição perdurou em quase todo o litoral até o contato com os Tupi-guarani, e em algumas áreas - baía de Guanabara e Ilha Grande -, até a chegada dos europeus, quando se originou a fase Neo-Brasileira denominada Magepê.

Ao longo de todo esse período, as restingas encontravam-se habitadas por macrobandos de pescadores da subfase Itaipu B, que mantém várias semelhanças com a fase Macaé. Essa indicação levou o próprio Mendonça de Souza a sugerir que a transição da subtradição Guapi para a fase Macaé se deu por influência da subfase Itaipu B (1981: 76-77), que perdurou também até a chegada dos Tupi-guaranis, tendo permanecido em Cabo Frio provavelmente até a vinda dos colonizadores. $\mathrm{O}$ autor supõe ainda que, pouco antes da chegada dos europeus, esta subfase já dispunha de algum tipo de agricultura.

A última fase pré-cerâmica corresponde à Pequerê, cujos sítios localizam-se em abrigos sob rocha na baía da Ilha Grande e em Arraial do Cabo, caracterizando-se por uma economia baseada em recursos marinhos e cultura material semelhante à da subtradição Guapi. Provavelmente ocupa posição intermediária entre esta e a subtradição Macaé, e, embora não existam datações disponíveis, o autor sugere que tenha perdurado até a chegada dos europeus.

No tocante à tradição Macaé, todas as quatro subtradições baseavam sua economia na coleta de molusco: a Mambucaba I, composta pelas fases Mambucaba I, Magé e terceira camada do sambaqui do Forte, caracterizava-se pela coleta de moluscos subsidiada pela pesca (Mendonça de Souza 1981: 45); a Guapi, composta pela fase Guapi, níveis inferiores dos sambaquis agrupados por Onde- 
mar Dias na fase Macaé e segunda camada do sambaqui do Forte, centrava-se na coleta generalizada subsidiada pela pesca (Mendonça de Souza 1981: 46); a Macaé, que conta com as fases Sernambi, Mambucaba II, a maioria dos sambaquis inseridos por Ondemar Dias na fase Macaé e dos que foram caracterizados como espessos por Salles Cunha em Sepetiba e Guaratiba, baseava-se na caça, pesca e coleta generalizada (Mendonça de Souza 1981: 46); a Magepê, composta pelos níveis superiores do sambaqui do Rio das Pedrinhas, sambaqui de Saracuruna, de Sernambetiba e outros da área de Magé, sambaqui da Trindade I,I,III, sambaquis de Angra dos Reis estudados por Ondemar Dias e alguns pequenos sambaquis de Guaratiba descritos por Salles Cunha, apresenta modificações ligeiras no padrão de consumo (Mendonça de Souza 1981: 66-67). As observações fornecidas referem-se apenas ao peso das atividades de coleta e pesca, sendo exceção apenas a subfase Macaé, onde se sugere o predomínio da caça.

Mendonça de Souza assinala que a tecnologia da cerâmica foi adquirida há cerca de 1500 anos por grupos de caçadores e recoletores do interior fluminense, dando origem à fase Mucuri, da tradição Una. É provável que essa tecnologia tenha provindo de Minas Gerais - fase Piumhi -, associada à prática da agricultura incipiente do milho. A fase Mucuri correlaciona-se com as fases litorâneas Una e Jabaquara, sendo associada pelo autor, provisoriamente, ao grupo tribal histórico Puri-coroado.

Iniciada há aproximadamente $\mathbf{1 . 0 0 0}$ anos e estendendo-se até a colonização, a fase Una está correlacionada, também de maneira provisória, com os Goitacá, e provavelmente caracteriza o momento em que grupos da tradição Itaipu adquiriram a tecnologia da cerâmica, da fase Tangui (Espírito Santo) ou da Mucuri. Circunscreve-se a alguns sítios nas proximidades do rio Una, em Cabo Frio, sítios esses que apresentam inventário cultural semelhante ao da subtradição Itaipu A, exceto pela presença de cerâmica. Mendonça de Souza assinala que esses sítios são testemunhos da permanência de padrões de subsistência centrados em recursos marinhos e estuarinos, bem como da prática incipiente da agricultura.

A fase Jabaquara tem os seus sítios localizados no extremo litoral sul fluminense, região de Parati, e revela a permanência dos padrões culturais da fase Pequerê, com sítios em abrigos sob rocha, apenas com o acréscimo da cerâmica. Embora não esteja datada, o autor, por analogia com outras áreas, propõe que se tenha instalado por volta de 800 anos passados, tendo permanecido, ao que tudo indica, até o contato com o europeu, quando deu origem à fase Neo-Brasileira Parati.

Por último, também há aproximadamente 800 anos, os Tupi-guarani atingiram o estado do Rio de Janeiro, segundo hipóteses levantadas por Mendonça de Souza, ou seguindo a direção de norte para sul, ou partindo de Minas Gerais, percorrendo diretamente o médio curso do Paraíba, ou ainda provindo do extremo norte paulista, acompanhando todo o curso do rio Paraíba do Sul. Segundo o autor, a ocupação contornou a área ocupada pela tradição Una, sendo possível a ocorrência de confronto com bandos de coletores de moluscos ou pescadores do litoral, que foram exterminados ou assimilados pelos Tupi-guarani.

Do prolongado contato de alguns grupos Tupiguarani com os europeus, originou-se a fase NeoBrasileira denominada Calundu, que se distribuiu pelo litoral rigorosamente nas mesmas áreas antes ocupadas pela tradição Tupiguarani. Finalmente, por volta de $\mathrm{AD} 1800$, com a ação missionária e a pressão dos colonizadores, as populações aborígenes do Rio de Janeiro já se encontravam praticamente extintas, pelo menos como etnias autônomas.

Nos esquemas desenvolvidos pelas equipes do ISCB e do IAB, quatro pontos diferenciais podem ser sublinhados:

1) os sítios do estado do Rio de Janeiro são classificados pelos pesquisadores do IAB apenas em fases e tradições, enquanto os do ISCB estabelecem ainda outras especificações, valendo-se de subtradições e subfases;

2) a equipe do $I A B$ não define uma tradição para associar os sítios denominados como Macaé, fase a que pertencem todos os testemunhos encontrados nesse conjunto, ainda que eventualmente tenham sido apontadas diferenciações no seu interior. Já os pesquisadores do ISCB descrevem a tradicão Macaé e a subdividem em quatro subtradições, compostas, por sua vez, de diferentes fases.

3) para a equipe do ISCB, a tradição Itaipu precede a tradição Macaé, tendo as duas resultado de migrações de grupos distintos (Mendonça de Souza 1981: 24-25 e Mendonça de Souza \& Mendonça de Souza 1981/82: 110). A primeira teria ocorrido de início nas serras fluminenses, e a segunda, no Sul do Brasil (Mendonça de Souza 1981: 24-25). Os 
pesquisadores do IAB caracterizam a tradição Itaipu como um desdobramento regional da fase Macaé, decorrente da adaptação dos primeiros grupos às mudanças climáticas.

4) o mosaico encontrado pelos europeus a que se refere Alfredo Mendonça de Souza (1981) pressupõe um período razoável de contemporaneidade entre os grupos pré-cerâmicos e cerâmicos, enquanto Ondemar Dias e Eliana Carvalho propõem ter havido contato apenas entre algumas fases Tupiguarani e Una. Sugerem também que as fases costeiras Tupiguarani apresentam indícios de aculturação com as fases pré-cerâmicas do litoral, porém, em nenhum momento indicam que as fases que identificam os primeiros habitantes da costa tenham permanecido até o contato com o europeu.

\section{Esquema proposto por}

Osvaldo Heredia e equipe do Museu Nacional

O sistema de fases proposto pelos pesquisadores do IAB foi contestado em diferentes oportunidades por Osvaldo Heredia e seus colaboradores, instalando-se um debate entre os representantes das duas vertentes (Heredia, Beltrão, Gaspar \& Gatti 1981/82: 182-185, Gatti, comunicação SAB de 1983). Em certa medida, é possível supor que o artigo de Ondemar Dias e Eliana Carvalho (19811982: 95-105) tenha constituído uma resposta a essas críticas.

A proposta de Heredia baseia-se nos resultados de prospecções realizadas em quase todo o estado do Rio de Janeiro, bem como de sondagens em 12 sítios distribuídos pelo litoral fluminense. Uma publicação do final da década de 1980 sistematiza toda a sua pesquisa, classificando os sítios estudados a partir dos ambientes em que estão situados, segundo as seguintes categorias: localizados em fundos de baías, próximo a manguezais; na beira de canais que ligam lagoas de restinga com o mar; em praias calmas de ilhas voltadas para o continente; em praias abertas, mas com alguma proteção natural; nas costas (dorsos) de praias marinhas abertas, sem proteção; e em terrenos de suave declive e rasos afetados pelas marés diárias (Heredia, Tenório, Gaspar \& Buarque 1989: 230239).

Temas como duração da ocupação, sazonalidade e caracterização do equipamento tecnológico são abordados, porém não estão claramente relacionados ao vetor classificatório, o que reduz a sín- tese a apenas uma descrição de sítios a partir de sua localização atual, podendo-se mesmo questionar o valor taxonômico das categorias utilizadas.

A ordenação dos dados com base em tais procedimentos, sem incluir os resultados obtidos por outros pesquisadores, não chega a configurar uma interpretação abrangente da ocupação da região. Cabe como destaque a grande homogeneidade cultural observada, apesar do registro de algumas diferenças nos tipos de recursos explorados e no equipamento tecnológico.

\section{Esquema proposto por \\ Maria da Conceição Beltrão e \\ Lina Kneip, do Museu Nacional, UFRJ}

Maria da Conceição Beltrão e Lina Kneip, também do Museu Nacional, diferentemente dos pesquisadores acima citados, apresentam um esquema alternativo de classificação dos vestígios arqueológicos em que as fases e tradições adotadas pela equipe do $I A B$ não são consideradas. Em outra ocasião, todavia, utilizam essa proposta (Beltrão \& Kneip 1969).

Em artigo de 1967, as pesquisadoras identificam três tipos de sítios:

1) os sambaquis, depósitos conchíferos acumulados por grupos tribais que dependiam essencialmente da coleta de moluscos e da pesca. Esses sítios foram distribuídos, segundo a localização, em três faixas de antigüidade:

a) aqueles cujas bases repousam em sedimentos hoje situados abaixo do nível do mar, podendo estar submersos ou parcialmente submersos, e que se inscrevem na faixa de idade entre 10.000 e 6.000 anos;

b) os sítios assentados sobre sedimentos que ficaram fora do alcance do mar no ápice do ótimo climático, e que estão na faixa de antigüidade entre 6.000 e 3.000 anos;

c) os sambaquis e outros sítios que contêm conchas assentados sobre sedimentos arenoargilosos, sempre inferiores a $1 \mathrm{~m}$, e que se inserem em faixa de antigüidade entre $3.000 \mathrm{e}$ 500 anos.

2) os aldeamentos Tupi, circulares e compostos de cabanas coletivas dispostas ao redor de uma praça quadrada, localizados às margens de riachos, próximos aos rios ou ao mar;

3) os acampamentos Tupi, sítios circulares, geralmente de 50m de diâmetro, com a espessu- 
ra da camada arqueológica em torno de $50 \mathrm{~cm}$ de profundidade, e que apresentam vestígios de estacas que correspondem a habitações. Estão situados próximo ao mar e junto a bancos de moluscos e ao mangue, em elevações de cerca de $50 \mathrm{~cm}$.

Baseando-se na classificação de Willey e Phillips (1962), Maria da Conceição Beltrão (1978) identifica posteriormente três estágios culturais: o estágio arcaico, representado pelos sambaquis, aldeias dos coroados e acampamentos Puri e Goitacá; o estágio formativo, representado apenas pelos Tupi-guarani, e o estágio lítico, para o qual a autora não indica os representantes.

\section{Balanço crítico da produção científica}

O esquema apresentado por Osvaldo Heredia e equipe, ainda que baseado em escavações sistemáticas de um número razoável de sítios, não chega a construir uma interpretação explicativa do processo de ocupação do Rio de Janeiro. A proposta de Maria da Conceição Beltrão e Lina Kneip, mais tarde retomada pela primeira, revela uma concepção bastante genérica e não dá conta da diversidade dos testemunhos arqueológicos registrados no estado. Devido a essas especificidades, serão analisadas, em detalhe, apenas as propostas do IAB e do ISCB, com ênfase especial no período pré-cerâmico.

Os dois quadros explicativos apresentam uma série de questões que serão tratadas em conjunto, mesmo porque, apesar das diferentes interpretações, muitos critérios classificatórios são recorrentes em ambas as abordagens. O ponto de partida dessa análise será o estudo do próprio esquema classificatório, com o objetivo de avaliar a sua procedência. Em seguida, serão discutidos os problemas levantados pelos pesquisadores e, depois, os pressupostos que estruturam o próprio esquema.

Um dos pontos críticos observados nos diferentes quadros propostos é justamente o critério classificatório. Todos os esquemas ordenam os vestígios arqueológicos, subdividindo-os segundo critérios passíveis de discussão. A questão que se impõe é avaliar a procedência da divisão estabelecida entre fase/tradição Macaé e tradição Itaipu e, conseqüentemente, os desmembramentos em subtradições, subfases e fa- ses no interior dos dois conjuntos mais abrangentes. Serão debatidas, inicialmente, as explicações para o surgimento da tradição Itaipu, seguindo-se o estudo do próprio esquema classificatório.

\section{O surgimento da tradição Itaipu}

Reforçando o que já foi apresentado, existem duas versões para explicar o sürgimento da tradição Itaipu. Alfredo Mendonça de Souza (1981: 25) considera que seja resultado de migração de grupos procedentes do interior do próprio estado, enquanto Ondemar Dias e Eliana Carvalho propõem uma vinculação com a fase Macaé.

Os pesquisadores do IAB sugerem que os grupos que formaram os sítios da tradição Itaipu estão relacionados com a fase Macaé, e as mudanças que justificam a formação de um novo conjunto resultam de uma adaptação aos movimentos marinhos. A variação do nível do mar é acionada para determinar a maior ou menor disponibilidade de moluscos, e sua escassez, decorrente das alterações climáticas, é associada à ausência de sítios da fase Macaé e ao surgimento da tradição Itaipu.

Para esquematizar as modificações que ocorreram no litoral fluminense, os dois autores baseiam-se na curva de Fairbridge, que estabelece a variação do nível do mar, porém já é apontada na literatura como inadequada para estudos regionais. Ab'Saber (1978/79/80: 48) chama atenção para o fato de que cada área apresenta flutuações locais sub-regionais que devem ser consideradas. Mesmo que, em termos gerais, ainda seja factível tomar essa curva como referência, para a escala em questão considerada ela se revela inapropriada, posto que a maioria dos sítios estudados situa-se numa faixa litorânea que dista apenas cinco quilômetros do mar, muitas vezes em regiões bastante planas.

Ondemar Dias faz menção à inexistência de sambaquis no período em torno 5000 e 4000 anos, tanto para o Rio de Janeiro (1978/79/80: 41-42) como para toda a costa brasileira (1981/82: 195), correlacionando a baixa incidência de sítios às mudanças ambientais que provocaram escassez de moluscos. No que se refere ao Rio de Janeiro, o argumento carece de fundamento, uma vez que não se pode estabelecer uma correspondência linear entre a falta de datações para esse período e a ausência de sítios. 
Convém lembrar que no momento em que tais reflexões foram feitas, contava-se com um número basțante reduzido de datações. Atualmente, em todo o estado do Rio de Janeiro, já se dispõe de 25 sítios datados, dos quais seis se referem ao período entre 5000 e 4000 anos (ver quadro de datações e gráfico na página seguinte). Tomando-se em consideração a região Sul-Sudeste como um todo, as informações apresentadas por Uchôa (1978/79/80: 23-30) indicam a presença de 35 sítios no período entre 5240 e 3865 AP, num universo de 54 sítios datados. Inclui-se nesse total a nova datação do sítio Maratuá, $3865 \pm 95 \mathrm{AP}$, que também o situa no período que foi caracterizado como de "escassez" de sambaquis.

À luz desses novos dados, os argumentos levantados para explicar o surgimento da tradição Itaipu parecem não ter se consolidado. Por outro lado, ainda não se conseguiu fixar a disponibilidade de moluscos através do tempo, e as recentes datações obtidas não confirmam a existência de um período no qual poucos sambaquis estavam ativos. Pouco provável também é a filiação da tradição Itaipu aos caçadores que "hipoteticamente" ocuparam o interior do estado do Rio de Janeiro.

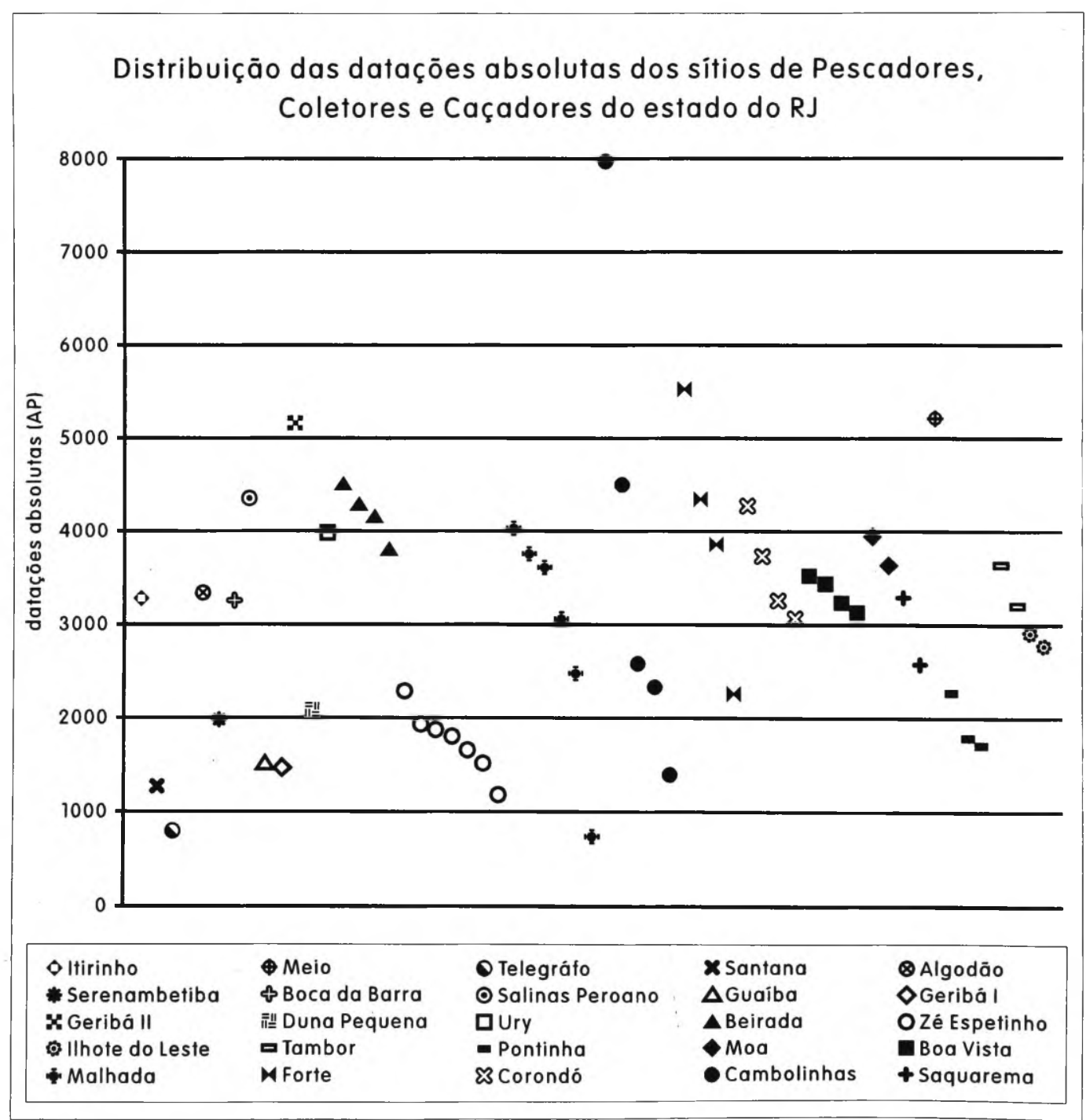


TABELA 1

\begin{tabular}{|c|c|c|}
\hline \multicolumn{3}{|c|}{ Datações Absolutas de sítios do Estado do Rio de Janeiro } \\
\hline Sítios & Datas(BP) & Referência Bibliográfica \\
\hline \multirow[t]{4}{*}{ Forte } & $5520 \pm 120$ & Kneip, L. /77 \\
\hline & $4330 \pm 140$ & \\
\hline & $3940 \pm 140$ & \\
\hline & $2240 \pm 70$ & \\
\hline \multirow[t]{4}{*}{ Corondó } & $4260 \pm 75$ & Carvalho, E. $/ 84$ \\
\hline & $3720 \pm 95$ & \\
\hline & $3215 \pm 90$ & \\
\hline & $3010 \pm 80$ & \\
\hline Ury & $3975 \pm 160$ & Dias, 0. $/ 69$ \\
\hline \multirow[t]{5}{*}{ Camboinhas } & $7958 \pm 224$ & Kneip, L. et al. $/ 81$ \\
\hline & $4475 \pm 160$ & \\
\hline & $2562 \pm 138$ & \\
\hline & $2328 \pm 136$ & \\
\hline & $1410 \pm 135$ & \\
\hline Duna Pequena & $2030 \pm 155$ & Kneip, L.; Pallestrini, L.; Cunha, F. /81 \\
\hline \multirow[t]{2}{*}{ Saquarema } & $3280 \pm 60$ & Kneip, L. $/ 95$ \\
\hline & $2550 \pm 60$ & \\
\hline \multirow[t]{4}{*}{ Beirada } & $4520 \pm 190$ & Kneip, L. et al. $/ 89$ \\
\hline & $4300 \pm 190$ & \\
\hline & $4160 \pm 180$ & \\
\hline & $3800 \pm 190$ & \\
\hline \multirow[t]{7}{*}{ Zé Espinho } & $2260 \pm 160$ & Kneip, L. /87 \\
\hline & $1920 \pm 150$ & \\
\hline & $1860 \pm 160$ & \\
\hline & $1780 \pm 170$ & \\
\hline & $1650 \pm 170$ & \\
\hline & $1510 \pm 160$ & \\
\hline & $1180 \pm 170$ & \\
\hline Santana & $1260 \pm 330$ & Lima, T.; Silva, R. /84 \\
\hline Algodão & $3350 \pm 80$ & Lima, T. $/ 91$ \\
\hline Sernambetiba & $1960 \pm 70$ & Gaspar, M.D. 191 \\
\hline Boca da Barra & $3260 \pm 180$ & Gaspar, M.D. inédito \\
\hline Salinas Peroano & $4340 \pm 70$ & Franco, T.; Gaspar, M. /92 \\
\hline Guaíba & $1520 \pm 60$ & Gaspar, M. /93 \\
\hline Geribá I & $1480 \pm 90$ & Gaspar, M. $/ 93$ \\
\hline Geribá II & $5150 \pm 110$ & Gaspar, M. $/ 93$ \\
\hline \multirow[t]{2}{*}{ Ihote do Leste } & $2910 \pm 90$ & Tenório, M.C. $/ 91$ \\
\hline & $2650 \pm 350$ & Tenório, 1995 \\
\hline \multirow[t]{2}{*}{ Tambor } & $3635 \pm 135$ & Dias, 0.169 \\
\hline & $3200 \pm 190$ & \\
\hline \multirow[t]{3}{*}{ Pontinha } & $2270 \pm 170$ & Kneip, L. et al. /91 \\
\hline & $1810 \pm 50$ & \\
\hline & $1790 \pm 40$ & \\
\hline Telegráfo & $800 \pm 100$ & Schmitz, P. /80\# \\
\hline \multirow[t]{2}{*}{ Moa } & $3960 \pm 200$ & Kneip, L.et al. $/ 91$ \\
\hline & $3610 \pm 190$ & \\
\hline \multirow[t]{4}{*}{ Boa Vista } & $3480 \pm 100$ & Gaspar, M.D.; Barbosa, M.; Barbosa, D.R./94 \\
\hline & $3110 \pm 60$ & \\
\hline & $3210 \pm 50$ & \\
\hline & $3410 \pm 60$ & \\
\hline \multirow[t]{6}{*}{ Malhada } & $4020 \pm 80$ & Dias, $0 . / 93$ \\
\hline & $3725 \pm 75$ & \\
\hline & $3580 \pm 80$ & \\
\hline & $3050 \pm 80$ & \\
\hline & $2455 \pm ?$ & \\
\hline & $710 \pm 60$ & \\
\hline Itirinho & $3270 \pm 70$ & Tenório, M.C. inédito \\
\hline Meio & $5180 \pm 80$ & Gaspar, M.D. inédito \\
\hline
\end{tabular}




\section{O esquema de classificação}

Na diferenciação das tradições, dois critérios estruturam os quadros propostos: localização e composição dos sítios. Esse último subdivide-se, por sua vez, em artefatos e restos alimentares. É a partir do comportamento desses vetores nos sítios que são construídas diferentes interpretações.

Para avaliar a procedência das observações, é necessário considerar inicialmente a amostra sobre a qual os pesquisadores se apoiaram para compor os diferentes conjuntos. Apesar de vários sítios terem sido cadastrados, os esquemas baseiam-se no estudo de um pequeno número deles, distribuídos de maneira desigual, tanto nos esquemas classificatórios propostos pelos diferentes grupos de pesquisadores (IAB e ISCB) como no interior dos diferentes conjuntos construídos (tradições, subtradições, fases e subfases).

É preciso ter em mente que a elaboração desses esquemas interpretativos praticamente coincide com a implantação dos primeiros projetos de pesquisa arqueológica no Brasil, quando havia apenas um pequeno número de sítios escavados e os dados disponíveis eram escassos. Os únicos sítios sobre os quais se podia contar com informações significativas e consistentes eram o Corondó e o Forte. No início da concepção do esquema interpretativo sobre a fase Macaé, Ondemar Dias pôde dispor ainda de um corte estratigráfico no sambaqui do Ury, porém, ao que tudo indica, quanto aos sítios da fase Itaipu B, os dados eram bastante reduzidos.

No desenvolvimento da pesquisa do ISCB, Sheila Mendonça de Souza realizou trabalho no sítio Colônia de Pesca, em Arraial do Cabo, associado à subtradição Itaipu B (Mendonça de Souza, Santos, Schram \& Miranda 1983/84: 110) e à sua base Itaipu A (Mendonça de Souza \& Mendonça de Souza 1981/82: 111), porém, os resultados publicados referem-se apenas à identificação de restos ósseos (Mendonça de Souza, Santos, Schram \& Miranda 1983/84: 107-119).

A equipe conta ainda com dados obtidos no sambaqui Rio das Pedrinhas, em Magé, considerado parcialmente das fases Magé, Guapi e Sernambi (Mendonça de Souza \& e Mendonça de Souza 1983), e com informações extraídas dos sítios localizados na baía da Illha Grande (Mendonça de Souza: 1977). Escavações no sambaqui do Praxedes, da fase Mambucaba, também foram feitas por Alfredo Mendonça de Souza, bem como corte de $1 \mathrm{~m}^{2}$ nos sítios
Parati-Mirim e Praia do Leste I e II, e escavação na toca do Cassununga, identificados como da fase Pequerê. O ISCB dispõe igualmente de informações coletadas através de sondagem no sambaqui de Saracuruna, filiado às fases Sernambi e Magepê-Mirim (Mello \& Mendonça de Souza 1977: 44).

Os resultados obtidos por Lina Kneip, em particular aqueles referentes ao sambaqui do Forte, em Cabo Frio, e Camboinhas e Duna Pequena, em Itaipu, são incorporados de diferentes maneiras nas duas sínteses apresentadas. Os pesquisadores do IAB identificam o Forte como sendo parcialmente da fase Macaé e da tradição Itaipu, ao passo que os do ISCB o associam na sua totalidade à tradição Macaé, subdividindo-o, porém, em subtradição Mambucaba, Guapi e Magepê. A equipe do ISCB caracteriza o sambaqui de Camboinhas como pertencente às subfases Itaipu A e B, e Duna Pequena como de subfase Itaipu B (Mendonça de Souza \& Mendonça de Souza 1981/82: 111), sendo este último identificado pelos pesquisadores do IAB como de tradição Itaipu (Ondemar Dias 1978/79/80: 35).

Embora pelo menos 14 sítios tenham sido pesquisados até o final da década de 1980, número que poderia ser considerado razoável para configurar a ocupação pré-cerâmica, é preciso ressaltar que nem todos os dados sobre todos os sítios estão disponíveis para a comunidade de arqueólogos. Apenas os resultados das pesquisas realizadas no Corondó e no Rio das Pedrinhas, além dos estudos de Lina Kneip, foram amplamente divulgados. Se considerarmos ainda as subdivisões propostas fases, subfases, tradições e subtradições - nos diferentes esquemas, ver-se-á que a maioria dos conjuntos apresenta um pequeno número de elementos portadores de informações significativas.

Cada esquema interpretativo foi construído, portanto, a partir de amostras de tamanho reduzido e variável, coletadas em diferentes áreas dos sítios. A maneira como os dados são tratados em ambos os casos sugere a existência de certo consenso sobre a homogeneidade horizontal de todos os sítios, mesmo entre aqueles em que foram identificadas diferentes fases ou subfases. As estruturas de habitação e enterramentos, todavia, parecem indicar que o espaço interno do sítio, ao contrário do que se supõe, é diferenciado, pelo menos em relação a alguns tipos de vestígios (Gaspar \& De Blasis 1991; Gaspar, Barbosa \& Barbosa 1994; e Barbosa, Gaspar \& Barbosa 1994). A própria distribuição dos esqueletos no Corondó (Carvalho 1984: 202 e Ma- 
chado 1984: 115) e dos restos alimentares no Malhada (Dias 1978/89/80: 38) confirmam a suspeita de que a pretensa homogeneidade horizontal não está fundamentada. Dessa forma, é bem possível que certas particularidades utilizadas para a diferenciação entre fases e tradições resultem de diferenciações espaciais no interior do própio sítio.

\subsection{Localização}

Um dos critérios utilizados na elaboração do esquema interpretativo é a localização dos sítios, o que, em certa medida, antecipa uma das preocupações recorrentes da arqueologia atual. Porém, como é de se esperar em um trabalho precursor, não parece haver pesquisa sistemática com o auxílio de mapas em escala adequada, ou fotografias aéreas. Também não se encontram estudos que demonstrem a sistematização dos dados ambientais e que apresentem a hierarquização dos diferentes fenômenos naturais que influenciaram a escolha de determinados pontos do estado do Rio de Janeiro. O estudo de material cartográfico teria fornecido, sem dúvida, uma visão mais abrangente da distribuição espacial dos sítios e da inserção ambiental.

As categorias locacionais adotadas nos diferentes esquemas - cantos de praia, sobre dunas, corrente de ressurgência, distante de estuários de rio etc. - são apenas descritivas, resultando em uma avaliação fragmentada da implantação ambiental dos sítios. Essa observação também é válida para os outros esquemas. No que se refere às pesquisas recentes, embora muito se tenha avançado, ainda não foram superados os problemas de reconstituição ambiental. Praticamente todos os estudos se apóiam fortemente nas feições do ambiente atual. Um passo nesse sentido parece que está sendo dado por Rita Scheel (Schell, Ybert \& Gaspar 1996) com o estudo de antracologia.

Quanto à localização, está claro que os sítios da fase/tradição Macaé compartilham a mesma área que os sítios da tradição Itaipu. Segundo Ondemar Dias (1978/79/80: 36), alguns sítios da tradição Itaipu estão sobre os sambaquis, e os exemplos oferecidos pelos pesquisadores do IAB indicam que podem também ocorrer lado a lado. É o caso do sambaqui do Forte, parcialmente Macaé e Itaipu e contíguo à Duna da Boa Vista, sítio identificado com a tradição Itaipu, bem como do sambaqui de Camboinhas, da fase Macaé, e Duna Pequena e Duna Grande, da tradição Itaipu.
Ainda que o esquema proposto pela equipe do ISCB apresente diferenciações no tocante à associação de alguns sítios com fases e tradições, percebe-se também que as tradições Macaé e Itaipu ocupam a mesma área. No caso das fases Itaipu A e $\mathrm{B}$, assinala-se como elemento diferenciador o fato de a primeira ser mais interiorana do que a segunda, tendendo a localizar-se na beira de mangues e lagoas de águas paradas (Ondemar Dias, CEA: sp). Nesse caso, convém contextualizar a noção de interior, uma vez que o sítio Corondó, representante por excelência da fase Itaipu A, está situado a apenas nove quilômetros da costa, às margens de uma antiga lagoa, numa faixa que, a meu ver, embora não seja de beira-mar, como a grande maioria dos sítios, pode ser considerada como litorânea.

Em todos os esquemas, os sítios da fase Itaipu B ocupam praias de mar aberto sobre dunas. E como também são caracterizados por se localizarem no canto da praia, sendo importante a presença da barra de lagoas, pode-se supor que os ambientes associados às fases A e B apresentam mais semelhanças do que diferenças. Nas extremidades das praias de mar aberto, sobretudo se houver canal de uma lagoa, tende a se formar uma pequena enseada, e muitas vezes ocorre a presença de mangue. Esse é o caso do sambaqui do Forte.

A localização à beira de lagoas, por sua vez, não se opõe à localização nas proximidades do mar. $\mathrm{Na}$ restinga de Massambaba, o sítio Brejo do Mato I e os demais que lhe são próximos, situam-se às margens da lagoa e distam apenas quinhentos metros da praia de mar aberto. Dessa forma, podese dizer que conjugam atributos tanto da tradição Itaipu A como da tradição B.

$\mathrm{Na}$ prática, o elemento que parece definir o enquadramento de sítios nessa fase é o fato de estarem situados sobre duna. A denominação "sítio sobre duna" é recorrente nos cadastros e tem valor explicativo semelhante à palavra sambaqui (cf. Mendonça de Souza \& Mendonça de Souza 1981/ 82: 111). Porém, o fato de o sítio estar sobre dunas não significa que apresente necessariamente as características atribuídas aos sítios identificados com a fase Itaipu B, como é o caso do sambaqui de Camboinhas, sobre duna (Cunha \& Francisco 1981: 15), mas identificado com a tradição Macaé (Mendonça de Souza 1981).

A diferenciação da subtradição Itaipu apóiase ainda, segundo a equipe do ISCB, na constatação de que, para os grupos da subtradição Itaipu 
B, foi importante a presença de correntes de ressurgência, que fertilizavam as águas e as tornavam mais piscosas (Mendonça de Souza 1981). Essa correlação, a meu ver, não constitui um bom parâmetro, posto que apenas nas proximidades de Cabo Frio tal fenômeno está plenamente comprovado, não se tendo notícias de outras correntes de ressurgência em áreas onde ocorrem sítios da subtradição İtaipu B.

Aponta-se também que os sítios se encontram sempre longe dos estuários dos rios, em trechos do litoral onde as únicas possibilidades de obtenção de água potável são a captação de águas pluviais ou a escavação de poços nas areias. Tal característica, todavia, não é exclusiva dos sítios da subtradição $B$, principalmente porque há grande incidência de sítios dessa subtradição muito próximos de sítios da tradição Macaé. Utilizando a classificação proposta por Mendonça de Souza, os exemplos do sambaqui do Forte (tradição Macaé), próximo da Duna da Boa Vista (tradição Itaipu), e do sambaqui de Camboinhas (tradicão Macaé), com Duna Pequena e Duna Grande (tradição Itaipu), reforçam a hipótese de que a subtradição Itaipu B compartilhou o mesmo ambiente da tradição Macaé.

Os atributos escolhidos para estabelecer a diferenciação dos sítios - interior ou litoral, mangue e lagoas ou praias de mar aberto, sobre dunas ou não, ausência ou presença de corrente de ressurgência, ausência ou presença de rios - não são exclusivos de cada fase ou tradição. A fragilidade dos critérios adotados foi insinuada pela equipe do IAB (Dias \& Carvalho 1983/84: 100), que constatou terem os sítios da fase Macaé e da tradição Itaipu como ponto de contato a proximidade geográfica e ambiental. Com base nessa assertiva, a localização, um dos vetores estruturadores dos esquemas, não pode ser considerada como critério relevante para diferenciar a fase/tradição Macaé da tradição Itaipu.

\subsection{A composição dos sítios}

\section{Os artefatos}

$\mathrm{O}$ fato de, no momento em que os esquemas explicativos foram elaborados, ainda não se dispor de uma quantidade suficiente de dados sobre artefatos parece ter motivado uma preocupação especial em relação a determinadas peças, sobretudo aquelas relacionadas com o processamento de vegetais.
Com isso, os artefatos transformados em elementos classificatórios não foram aqueles que ocorrem de maneira abundante em todos os sítios, tais como pontas ósseas ou lascas de quartzo, que, sem dúvida, seriam adequados a um tratamento comparativo. A quantidade dos artefatos destacados - seixos ou blocos que podem ter sido utilizados para processar alimentos, comumente chamados de moletas, almofarizes, mãos-de-mó, mós, moinhos planos é bastante reduzida, em termos gerais, e mesmo nos sítios onde foram recuperados exemplares.

Classificar os sítios a partir de testemunhos numericamente pouco representativos põe em foco muito mais as diferenças do que as semelhanças. Por outro lado, essa opção torna a questão da amostragem ainda mais problemática, pois há grande probabilidade de que, em cortes de pequenas dimensões, tais peças não sejam recuperadas.

Como exemplo da variação quantitativa das diferentes classes de artefatos, serão apresentados os dados referentes ao sítio Corondó, enunciados por Eliana Carvalho (1984). A indústria óssea é composta por 396 exemplares (p. 143), a conchífera, por 1.352 (p. 180), tendo sido identificados 299 artefatos da indústria lítica num total de 1.923 peças recuperadas (p. 103), das quais apenas 44 apresentam indícios de terem sido utilizadas para moer (p. 101). Esse número, porém, não se refere a todos artefatos utilizados no processamento de alimentos, já que parte significativa das peças parece ter sido usada para macerar corante (p. 68). $O$ artefato cujo nexo com a preparação de alimentos é considerado indiscutível - o almofariz - está presente em apenas um exemplar (p. 95).

No tocante à distribuição das peças escolhidas como vetor classificatório, não há evidências de ter sido realizado um trabalho quantitativo que indicasse maior incidência de moletas e almofarizes nos sítios da fase Itaipu B do que nos demais sítios, considerando-se que tais artefatos não são exclusivos desta fase. Convém lembrar que os problemas amostrais já sublinhados tornam-se mais graves devido à baixa incidência desse tipo de material.

Por outro lado, os artefatos para processar alimentos não estão particularmente relacionados com a tradição Itaipu. Sítios como o sambaqui de Sernambetiba, em Magé, onde foram registradas várias mãos-de-pilão (Beltrão, Heredia, Rabelo \& Perez 1981/82: 100), e o sambaqui de Amourins, onde foram recuperados cinco fragmentos de diferentes almofarizes e 39 mãos-de-mó (Heredia, Beltrão, 
Gaspar de Oliveira \& Gatti 1981/82: 180), foram identificados por Alfredo Mendonça de Souza (1981) com a tradição Macaé, e, embora não tenham sido nomeados pelos pesquisadores do IAB quando apresentaram esta fase, muito provavelmente estão incluídos na categoria "sambaquis fluminenses", utilizada por Ondemar Dias.

Os artefatos escolhidos apresentam ainda características que dificultam a determinação de suas funções específicas. Se parece claro que os almofarizes estão relacionados com o processamento de alimentos, a mesma certeza não se aplica às peças ativas - moletas, mãos-de-mó-, até porque, muitas vezes, estas têm função múltipla. As marcas de ocre observadas no material do Corondó parecem indicar que estavam também associados à preparação de corantes.

A pesquisa que investiu no estudo dos restos numericamente mais abundantes (Dias \& Carvalho 1983/84: 95-105) deixa transparecer uma certa homogeneidade das indústrias lítica e óssea, das estruturas e dos sepultamentos. As diferenças observadas na indústria lítica referem-se apenas à quantidade, aos "processos preliminares" e seu emprego. Essa inferência diz respeito muito provavelmente ao material elaborado em quartzo, abundante em todos os sítios pré-cerâmicos.

Quanto à variação quantitativa, é importante frisar os problemas amostrais já tantas vezes sublinhados. No que se refere ao artefato em quartzo denominado "ponta", considerado traço diagnóstico da fase Itaipu (Dias 1969: 9), deve-se ressaltar o seguinte aspecto: não são poucos os obstáculos que se interpõem a uma identificação precisa do uso de artefatos elaborados nessa matéria-prima, que tem como característica intrínseca fragmentar-se em inúmeras partes e de formas variadas, o que torna difícil determinar a função apenas através da morfologia. Por outro lado, não se tem notícias de análise tecnológica que permita estabelecer semelhanças relacionadas aos aspectos preliminares, ou estudos traceológicos voltados à configuração de função.

Os autores assinalam a analogia da indústria óssea na fase Macaé e na tradição Itaipu, particularizando-se apenas quanto à sua relação com os outros restos, que todavia não são nomeados. Caso sejam relativos à indústria lítica, já foram apontadas as dificuldades que se apresentam no trato com esse material.

Ondemar Dias e Eliana Carvalho consideram ainda que a fase Macaé e a tradição Itaipu com- partilham de "certos padrões de enterramento", embora ocorram em quantidade distinta em cada sítio. Mais uma vez é necessário enfatizar que as questões quantitativas estão comprometidas pela amostragem, afirmativa que nesse caso se mostra particularmente verdadeira. A missão de 1978 realizada no Corondó (Carvalho 1984: 203), ao escavar uma área de $34 \mathrm{~m}^{2}$, recuperou apenas seis sepultamentos. Porém, no setor vizinho LA-15, de $4 \mathrm{~m}^{2}$, trabalhado em outra missão, foram encontrados 52 esqueletos. Essa distribuição diferenciada dos sepultamentos não passou desapercebida à autora, que considerou o setor LA-15 como "zona core" de sepultamentos (1984: 202). ${ }^{2}$ O registro, pelos pesquisadores, de um mesmo padrão de enterramento, nesse caso específico, compromete a classificação proposta, não se podendo aceitar a quantidade de esqueletos como elemento diferenciador entre a fase Macaé e a tradição Itaipu.

Por último, cabe menção às estruturas de paliçadas, cabanas e marcas de estacas, que, para os autores, são comuns aos sítios da tradição Itaipu, apresentando-se, todavia, apenas esboçadas nos sítios da fase Macaé. Esse aspecto não configura uma real distinção. Ao contrário, o fato de essas estruturas ocorrerem tanto nos sítios identificados com a fase Macaé como com a tradição Itaipu evidencia, na realidade, uma característica comum aos dois conjuntos de sítios, indicando que todos foram locais de habitação e que sobre eles os moradores construíram estruturas de abrigo.

Com base no que foi descrito, pode-se considerar que os artefatos mais abundantes estão assinalando uma certa homogeneidade entre as tradições. Os artefatos destacados para caracterizar uma das tradições - peças para moer - devem ser tratados com reservas, devido a problemas amostrais e a dificuldade em estabelecer função, enquanto aqueles registrados nos sítios pré-cerâmicos não estão apontando para a definição de conjuntos realmente diferenciados.

\section{Restos faunísticos}

A composição dos sítios tem sido um atributo utilizado para identificar fases e tradições. Referese principalmente à caracterização dos restos ali-

(2) Lina Kneip et alii (1987: 254) faz observação semelhante em relação à distribuição dos esqueletos no sítio Zé Espinho. 
mentares, à proporção de conchas e ossos de peixe e à maneira como estão distribuídos - formando camadas compactas, ou de maneira esparsa. Por outro lado, é também considerada como um elemento indicador da economia dos grupos que os construíram.

As observações dos pesquisadores sobre economia nos diversos esquemas suscitaram três tipos de problema: 1) a forma como foi estabelecido o predomínio das atividades de coleta ou de pesca; 2) a presença de agricultura; e 3 ) a própria noção de economia - a concepção de economia que perpassa os esquemas explicaticos será discutida mais adiante.

Os esquemas apreciados, apesar de atribuírem origem diversa para a fase/tradição Macaé e a tradição Itaipu, concordam no tocante à diferenciação dos restos alimentares dos grupos associados a ambas. A fase/tradição Macaé caracterizar-se-ia pelo predomínio de consumo de moluscos, e a tradição Itaipu, pela intensificação da pesca, embora a coleta ainda persista.

Nas duas propostas, a passagem de coleta de moluscos para a intensificação da pesca mantém estreita relação com as alterações climáticas e, em particular, com as variações do nível do mar e a menor disponibilidade de moluscos. Para os pesquisadores, a constatação do incremento da pesca está legitimada sobretudo pelos resultados dos estudos no sambaqui do Forte, bem expressos nos artigos de Lina Kneip (1977 e 1980), onde a autora estabelece a seqüência cultural da ocupação e as respectivas datações.

Embora as informações disponíveis sobre o sambaqui do Forte sejam mencionadas reiteradamente para justificar a divisão em fases e tradições, cabe perguntar se as alterações detectadas por Kneip $(1977,1980)$ respaldam as diferentes leituras feitas pelos pesquisadores.

Os argumentos que sustentam a proposta do incremento da pesca em detrimento da coleta são as mudanças climáticas, em especial, as oscilações do nível do mar, apoiadas na curva de Fairbridge - sobre a qual já foram apresentadas reservas. Segundo esse esquema interpretativo, as alterações do nível do mar seriam o elemento determinante do incremento da pesca em detrimento da coleta. As alterações climáticas, sobretudo o aumento da temperatura, teriam repercussão sobre a oferta de moluscos, levando, em conseqüência, ao desenvolvimento da pesca. $\mathrm{O}$ argumento justificativo é que, uma vez constatadas alterações ambientais, firma- se a correspondência estreita com os fenômenos culturais. Entretanto, como já foi salientado, ainda não estão disponíveis para o Rio de Janeiro levantamentos que considerem as diferentes temperaturas para o quaternário, nem o estudo sistemático sobre abundância de moluscos.

O exemplo do sítio Illhote do Leste, onde o predomínio da pesca antecedeu a coleta de molusco (Tenório: 1991), contrapõe-se à sequiência apresentada. Mesmo que a análise de um único sítio não permita contestar a interpretação proposta, as datações de Sernambetiba e Amourins, de $1960 \pm 70$ $\mathrm{AP}$ e $3530 \pm 60 \mathrm{AP}$, respectivamente, ambos localizados no fundo da baía de Guanabara, são suficientes para questioná-la. O sambaqui de Sernambetiba é composto quase exclusivamente de restos de conchas que indicam a importância da coleta de moluscos, e análise dos restos faunísticos do sambaqui de Amourins aponta para a existência de maior ênfase na pesca do que em outros sítios (Heredia, Beltrão, Gaspar de Oliveira \& Gatti 1981: 82).

Por outro lado, se considerarmos apenas a aparência das camadas arqueológicas, os sítios Zé Espinho (Kneip 1987: 110) e Salinas Peroano (Heredia, Gaspar, Gatti \& Franco, mimeo; e Franco \& Gaspar 1991) também permitem relativizar a sequiência proposta, posto que, em ambos, a camada que apresenta maior quantidade de conchas também se encontra nos últimos períodos de ocupação. É preciso ressaltar, todavia, que a caracterização dos sítios com base na sua aparência implica riscos, ampliando as possibilidades de erro. Ondemar Dias (1978/79/80: 38) aponta para esse perigo, uma vez que ele próprio incorreu em erro ao classificar o sítio Malhada como sambaqui (fase Macaé), após analisar apenas uma área do sítio onde predominava a ocorrência Pomacea caniculata (Lamarck). Mais tarde, quando se verificou que as conchas de caramujos não eram os restos alimentares predominantes, o sítio foi enquadrado na tradição Itaipu.

Em recente estudo de zooarqueologia realizado em sítios da baia da Ribeira Algodão, Major, Peri, Bigode, Caieira I e II - e em Macaé - Ilha de Santana -, Lima (1991) informa ter constatado uma evolução econômica da coleta de molusco à pesca. Essa constatação não se coaduna com os resultados de outra pesquisa elaborada com princípios semelhantes. As reflexões de Levi Figuti (1995) e os resultados de estudos de restos alimentares em sambaquis de São Paulo, na Ilha do Casqueirinho (Figuti 1993) e de Santa Catarina - Espinheiros II 
- (De Blasis \& Afonso 1996) indicam que a pesca sempre foi uma atividade importante e sugerem que os restos alimentares que compõem esse tipo de sítios não decorrem exclusivamente de descarte alimentar. Esses trabalhos, porém, são recentes, e seus resultados ainda precisam ser confrontados.

Do meu ponto de vista, somente a partir de pesquisas que estudem os restos faunísticos de maneira sistemática - como nos recentes estudos - e considerem a ordenação espacial interna ao sítios poder-se-á determinar a real importância de moluscos e peixes para os grupos pré-históricos, já que os vestígios das duas atividades apresentam especificidades quanto ao volume dos restos e às suas características enquanto material de construção.

Os esquemas apresentados, ainda que apontem para a existência de diferenças no conteúdo dos sítios, não permitem inferir que as populações précerâmicas passaram por um ciclo evolutivo com início na coleta e desenvolvimento posterior da pesca intensiva, bem como que a fase/tradição Macaé e a tradição Itaipu correspondam a momentos distintos desse mesmo ciclo evolutivo.

A análise dos esquemas de fases e tradições permite identificar ainda outros três pontos problemáticos e que devem ser tratados em detalhe: a prática de atividades agrícolas pelos grupos que ocuparam os sítios identificados com a tradição Itaipu; a presença de cerâmica nos últimos níveis dos sítios da fase/tradição Macaé e da tradição Itaipu; e a própria concepção dos esquemas interpretativos.

\section{A prática de agricultura}

Nos esquemas interpretativos em pauta, os indicadores de atividade agrícola são também vetores que caracterizam a tradição Itaipu e a diferenciam da fase/tradição Macaé. A existência de agricultura incipiente no litoral do Rio de Janeiro há cerca de 4.000 anos é um tema que tem gerado intensa polêmica. Ondemar Dias e Eliana Carvalho têm investido especialmente na defesa dessa hipótese, também apoiada por Alfredo Mendonça de Souza (1981). Para uma apreciação desse enfoque, serão enunciados os argumentos em que se funda a explicação teórica da equipe do IAB para a domesticação de vegetais, seguindo-se a análise dos indicadores locais que estruturaram essa hipótese.

Ondemar Dias e Eliana Carvalho (1981/82: 193-194), apoiados na leitura de Binford (1968), sugerem que as mudanças climáticas ocorridas no Holoceno antigo e médio teriam provocado o desenvolvimento, no litoral, de espécies animais que se constituíam em excelentes fornecedores de proteínas para populações. No interior, a abundância de recursos teria sido proporcionada pelo aumento das florestas. Nas duas regiões, a maior oferta de alimentos resultou no crescimento demográfico das comunidades de caçadores e coletores.

Esse crescimento é considerado pelos autores como um fator altamente estimulante e que teve as seguintes conseqüências: 1) gerou o rápido esgotamento de recursos naturais, o que levou à procura de elementos substitutivos; 2) impulsionou a procura de dietas equilibradas para a manutenção das comunidades, o que possibilitou o desenvolvimento de novos padrões alimentares, a partir de espécies que melhor respondessem à manipulação humana.

As comunidades do litoral teriam enfrentado o desequilíbrio entre consumo e produção, migrando para áreas interioranas. $O$ fluxo dos grupos nessa direção teria sido o fator decisivo que produziu o incentivo necessário para a domesticação gradual de elementos vegetais que respondiam favoravelmente à seleção.

Hassan (1978: 74), ao criticar as explicações para o surgimento da agricultura que conferem ao aumento demográfico um atributo motivador da transformação cultural, afirma que estas partem de um erro conceitual, ao confundir crescimento com pressão demográfica, uma vez que o primeiro não implica necessariamente em esgotamento de recursos. Considera ainda equivocada a suposição de que populações humanas cresceram desordenadamente até o extremo da fome e da miséria (1978: 72), apoiando seu argumento na constatação de que os mecanismos de controle populacional eram amplamente difundidos e utilizados com freqüência (1978: 71-73; e 1981: 121). Ressalta também que, embora existam evidências de crescimento populacional no final do Pleistoceno, o aumento populacional per se não constitui uma causa suficientemente forte para determinar mudanças culturais, e tampouco mudanças ambientais explicam automaticamente a transição econômica (1978: 212213).

No que se refere à migração como solução apontada para a crise entre consumo e produção, julga equivocado supor que a agricultura teria sido introduzida por refugiados e pelos grupos que os receberam, e se atornaram adensados com os re- 
cém-chegados. Essa proposta, a seu ver, não contempla a sociologia da imigração e sobretudo os controles culturais que regulam o movimento de pessoas entre diferentes grupos (1978: 81). Considera já ter sido demonstrado o fracasso dos modelos monocausais de pressão populacional para explicar a origem da agricultura, especialmente porque as populações sempre experimentaram flutuações. Se o crescimento populacional não fosse controlado, a agricultura provavelmente teria sido inventada há muito tempo (1978: 82).

O sistema defendido por Ondemar Dias e Eliana Carvalho apóia-se na idéia de que uma situação crítica aumento populacional e escassez de alimento teria constituído o elemento desencadeador do surgimento da agricultura. Contrapondo-se a essa hipótese, a pesquisa de Tenório (1991) enfatiza a importância da coleta no advento da agricultura, caracterizado como um processo lento para o qual é imprescindível o conhecimento acumulado dos fenômenos naturais dẹ reprodução/produção vegetal.

Do meu ponto de vista, a principal restrição ao esquema interpretativo dos pesquisadores do IAB vincula-se à inexistência de uma avaliação precisa das mudanças ambientais ocorridas na região apreciada, bem como do crescimento populacional e de suas possíveis conseqüências no contexto em questão. Finalmente, apoiada em Hassan (1978: 83) considero que a agricultura não se caracteriza por ser um empreendimento súbito, mas um processo gradual iniciado pela ênfase na coleta, sem inovações tecnológicas de quaisquer espécies nos estágios iniciais, mas com as vantagens dessa exploração levando eventualmente ao seu surgimento. Assim, o esquema que sugere que o estado do Rio de Janeiro tenha sido um foco de domesticação de vegetais precisa ainda apontar etapas desde o início do cultivo até sua importância efetiva na dieta alimentar.

A prática de agricultura da tradição Itaipu merece discussão mais prolongada. Os argumentos seguem a ordenação apresentada pela equipe do IAB.

A abundância de moletas e almofarizes, artefato comumente relacionado à preparação de alimentos, parece ter sido o primeiro elemento que fundamentaria a existência de agricultura incipiente. Alfredo e Sheila Mendonça de Souza (Mendonça de Souza 1981; e Mendonça de Souza \& Mendonça de Souza 1981/82: 113) apesar de não terem avançado nesse ponto, concordam com a associação estabelecida entre a presença de artefatos para moer/triturar e a agricultura. Já Ondemar Dias (1978/79/80: 34), ao mesmo tempo que sugere que os artefatos poderiam estar ligados à fabricação da farinha de peixe, indaga por que estes não poderiam assinalar a presença da agricultura, já que se referem a um horizonte recente, próximo à era cristã. Pelo exposto, parece tratar-se da fase Itaipu B, e a datação que serve como referência é da fase Potiri, no Espírito Santo.

Mais tarde, o início da agricultura incipiente é antecipado para a fase Itaipu A, talvez em decorrência dos trabalhos no sítio Corondó, particularmente o estudo de antropologia física realizado por Lilia Machado, e o argumento do horizonte recente perde a eficácia.

Turner e Machado (1981/82) estudaram o padrão de desgaste dentário e a incidência de cárie na população do Corondó, constatando que $89 \%$ dos crânios dos adultos apresentam abrasão da superfície lingual dos dentes anteriores superiores (ASLDAS), decorrente, a seu ver, do uso habitual dos dentes superiores para retalhar ou descascar material vegetal abrasivo com propósitos alimentares. Descartaram a possibilidade de o ASLDAS, que ocorre tanto entre homens e mulheres, jovens e adultos, ter resultado de atividades artesanais, já que consideram que tais atividades tendem a ser diferenciadas por papéis sexuais.

Os autores correlacionam o ASLDAS a uma ocorrência muito alta de cáries dentárias ( $81 \%$ dos adultos têm uma ou mais cáries), superior ao que se poderia esperar em um grupo presumivelmente agricultor. Argumentam que o consumo de mandioca (Manihot esculenta) e, conseqüentemente, de carbohidrato, explicaria tanto o elevado percentual de cáries como o desgaste, caso o vegetal fosse descascado com os dentes em movimento semelhante ao que se faz quando se come alcachofra. A hipótese de a cárie decorrer exclusivamente do consumo de carbohidrato poderia indicar a coleta intensiva de vegetais, como é o caso, citado pelos próprios autores, dos indígenas do vale do Sacramento, na Califórnia. No Brasil, estudo de Alvim (1977) sobre a região arqueológica de Lagoa Santa também associa a alta de incidência de cáries à coleta.

Se a correlação entre cárie e carbohidrato tende a se confirmar como positiva, o mesmo não se pode dizer da associação entre cárie e agricultura, ou mesmo entre o desgaste dos dentes e o consumo 
de mandioca. Parece ainda particular a combinação entre alta incidência de cárie, desgaste dentário e ingestão de alimentos cultivados. Segundo Neves, Unger e Scaramuzza (1984: 373), se a introdução de cultígenos na dieta alimentar acarreta aumento significativo de cárie, a situação tende a se inverter em relação ao desgaste, pois os alimentos que resultam da horticultura oferecem menor capacidade de abrasão.

Infelizmente, não existe estudo tão detalhado e quantitativamente significativo como o desenvolvido por Turner e Machado. Messias (1977: 166), na análise que fez nos 15 indivíduos da população do Forte, refere-se apenas à forma, à coloração e à robustez dos dentes - esse último item, muito provavelmente, pode ser traduzido como ausência de cárie. Os materiais recuperados pelo grupo de pesquisa a que estou vinculada ainda não foram analisados por um especialista segundo a mesma ótica, podendo-se afirmar, porém, sem dúvida, a partir das observações em laboratório, que não apresentam grande quantidade de cáries. Os estudos sobre os esqueletos recuperados nos sítios Massambaba e Boqueirão (Machado, Pons \& Silva 1989, a e b) também indicam que a incidência de cárie foi pouco expressiva.

Considerando as informações disponíveis sobre ausência de cárie nos outros sítios, parece claro que a população do sítio Corondó apresenta especificidades em relação a esse item. Nesse caso, é possível supor que a presença de cárie esteja associada à atividade agrícola, pois permanece sem explicação o fato de a população desse sítio ser a única a apresentar tão alta incidência. Caso o Corondó representasse de fato um foco de domesticação de plantas, como sugere o título do artigo de Ondemar Dias e Eliana Carvalho (1983), surpreende que o cultivo fosse desde o início tão importante na dieta alimentar, a ponto de proporcionar elevado índice de cárie já nos primeiros momentos de ocupação. Por outro lado, as etapas do processo que torna a agricultura efetivamente importante na dieta alimentar deveriam estar expressas no aumento progressivo de cáries em outros grupos (outros sítios) contemporâneos. $\mathrm{O}$ trabalho de Turner e Machado é fundamental para se estabelecer a dieta alimentar da população do Corondó, porém, a existência de atividade agrícola ainda deve ser melhor estudada.

A presença de almofarizes e moletas, $o$ alto índice de cáries e de desgaste dentário e ainda a possibilidade de que os inúmeros raspadores de concha recuperados no sítio Corondó fossem usados no preparo da mandioca (comunicação pessoal de Ondemar Dias, reunião SPHAN, 1987) sustentam a hipótese de que os grupos identificados como da fase Itaipu contassem com atividades agrícolas.

Durante a década de 1980, essa parece ter sido a questão central que ordenou as informações reunidas pela equipe do IAB para o período pré-cerâmico e estruturou a divisão entre fase Macaé e tradição Itaipu. Do meu ponto de vista, porém, ainda não existem evidências suficientes para estabelecer a existência de agricultura por volta de 4000 anos $\mathrm{AP}$ e, conseqüentemente, eleger a prática de atividade agrícola como critério diferenciador da fase/ tradição Macaé e da tradição Itaipur. As pesquisas continuam em andamento e, sem dúvida, esses pontos serão trabalhados.

\section{A presença da cerâmica}

Outra questão que se coloca é o significado da ocorrência de fragmentos de cerâmica nos últimos níveis de ocupação, em sítios identificados com a fase/tradição Macaé e a tradição Itaipu. $O$ resultado do estudo dessa classe de material mais uma vez foi a criação de várias fases. Na maioria dos sítios estudados, é comum a presença de cacos de cerâmica identificados com as tradiçoes Una, Tupiguarani e Neo-Brasileira nos últimos níveis de ocupação. Apesar da variação observada nesse material, um ponto em comum sobressai: os vários estudos (Dias 1978/79/80; Carvalho 1984; Mendonça de Souza 1977; e Kneip \& Pallestrini 1987) assinalam que a cerâmica é agregada ao material já existente, sem que se registre alteração no restante do conteúdo do sítio.

Antes de avançar nessa questão, é preciso esclarecer a que se refere a categoria de sítio proposta por Maria da Conceição Beltrão e Lina Kneip (1967), denominada "acampamento para coleta de moluscos". Convém ressaltar que, todos os autores consultados, com exceção de Maria da Conceição Beltrão (1978), que propôs e reafirmou a existência desse tipo de sítio, não fazem referência a qualquer testemunho arqueológico com as características da fase/tradição Macaé e da tradição Itaipu cujos vestígios tenham sido integralmente associados a grupos ceramistas. Lina Kneip, que em 1967 contribuiu na caracterização dos "acampamentos para 
coleta de moluscos", já no artigo de 1987 propõe uma reavaliação dessa categoria.

Interessa discutir a procedência do tipo de sítio proposto pelas autoras, caracterizados pela presença de "acampamentos Tupi-guarani para coleta de moluscos". Todas as referências encontradas sobre esses acampamentos (Dias 1976/77: 118; Prous 1977: 29; Scatamacchia 1981: 116; e provavelmente Mendonça de Souza 1977: 64) têm como matriz a proposta de Maria da Conceição Beltrão e Lina Kneip (1967). A existência desse tipo de sítio precisa ser esclarecida, pois a ocorrência de sítios voltados para a coleta de moluscos associados na sua totalidade à ocupação ceramista poderia levar a equívoco na concepção do processo de ocupação do estado do Rio de Janeiro. Para efeito dessa discussão, será mantida a dicotomia usada por Maria da Conceição Beltrão (1978) entre acampamentos para coleta de moluscos e sambaquis.

A autora propõe que os Tupinambá, para coletarem moluscos, deixavam suas aldeias, fixandose temporariamente nas proximidades dos bancos de moluscos, onde se instalavam em cabanas provisórias (1978: 117-118, 129-130). Baseando-se na análise da distribuição dos moluscos, sugere que, depois de dezenas de anos de ocupação, os acampamentos eram abandonados, em virtude do esgotamento dos bancos de moluscos.

Os vestígios dos acampamentos caracterizamnos como pequenos, de forma circular, com $50 \mathrm{~m}$ de diâmetro, em média, revelando uma camada arqueológica não superior a $50 \mathrm{~cm}$ de altura. Maria da Conceição Beltrão e Lina Kneip (1967: 4; e Beltrão, 1978: 117) registram, porém, não terem encontrado qualquer indicação desse tipo nas obras dos cronistas.

Alguns dos acampamentos citados por Maria da Conceição Beltrão estão localizados na planície de Guaratiba. Trabalho recente de Lina Kneip (1987: 75-88) apresenta levantamento exaustivo da área, tendo sido cadastrados 33 sítios, classificados pela pesquisadora, do ponto de vista morfológico e cultural, como sambaquis. O estudo detalhado de um desses sítios, o Zé Espinho, demonstra que a ocorrência de cerâmica restringe-se apenas à camada I (Crancio 1987: 165-175), relativa ao último momento de ocupação do sítio. É possível supor, baseando-se nos dados fornecidos por Lina Kneip, que a presença da cerâmica caracterizada como Tupiguarani também seja restrita aos últimos níveis nos demais sítios.
Com base no resultado da análise do sítio Zé Espinho, Crancio (1987: 174) propõe que a categoria "acampamento para coleta de moluscos" seja reavaliada. Lina Kneip e Pallestrini (1987: 225) também informam não terem encontrado evidências de que a população correspondente à camada cerâmica descrita alternasse as atividades de horticultura (nas aldeias) com atividades de coleta (nos acampamentos).

A presença de cerâmica nas superfícies dos sítios do litoral é um fenômeno amplamente difundido na região e, ao que parece, independente da forma e composição dos assentamentos. Por outro lado, a suposição de que os "acampamentos Tupi-guarani" teriam sido ocupados durante "dezenas de anos" pressupõe uma grande estabilidade, pelo menos vinte anos de permanência, o que se revela um período demasiadamente longo para os grupos em questão. Fernandes (1963: 10811) sugere que a frequiência das mudanças dos grupos Tupinambá era de quatro anos. Com base no que foi exposto, minha avaliação é de que os "acampamentos Tupi-guarani para coleta de moluscos " não constituem um tipo particular de sítio.

Retomando a questão relativa à presença de cerâmica nos sítios identificados com a fase/tradição Macaé e a tradição Itaipu, é importante assinalar que os esquemas em pauta registram sua ocorrência nos últimos níveis das ocupações. A associação da cerâmica com esses sítios é tão estreita que uma das características marcantes da fase Una é justamente ocorrer sobre os mesmos.

Para Ondemar Dias e Eliana Carvalho (1980: 53), a tradição Una, fase Una, corresponde a adaptações locais de grupos do interior há muito tempo fixados na costa. Mendonça de Souza (1981) assinala que a presença da cerâmica caracteriza o momento em que grupos da tradição Itaipu adquiriram essa técnica, e que os pacotes estratigráficos associados à tradição são testemunhos da permanência de padrões de subsistência centrados em recursos marinhos e estuarinos, bem como da prática de agricultura incipiente.

Os dois esquemas coincidem quanto ao próprio estabelecimento da tradição e à subdivisão em algumas fases, mas as explicações que tentam dar conta do seu surgimento são contraditórias. $O$ fundamental, porém, é que ambos admitem que a presença da cerâmica não está associada a alterações no restante do material, nem a aspectos morfológi- 
cos do sítio habitados por pescadores, coletores e caçadores.

A fase Jabaquara, segundo Alfredo Mendonça de Souza (1981: 75), também revela a permanência dos padrões culturais da fase Pequerê, que por sua vez apresenta conteúdo semelhante aos sítios identificados com a tradição Macaé. Por outro lado, existem sítios cadastrados identificados apenas com a tradição Una, dos quais são exemplos o Grande do Una (Una I), datado de $1060 \pm 90$ AP, Rio Una (Rio Una II), Pitangueiras e Novo do Una, todos na bacia do rio Una. Pelo menos em um deles, o Grande do Una, foi recuperado material abundante constituído de enterramentos em urnas, material lítico e ósseo, provavelmente semelhante ao da fase Mucuri. Ainda não existe, porém, uma síntese sobre esses sítios como a que já está disponível para a fase Mucuri (Dias \& Carvalho 1980: 43-86).

Considerando, como propõe o esquema de fases e tradições, que as fases do litoral (Una e Jabaquara) estão de alguma forma relacionadas com a do interior (Mucuri), a expectativa é que existam correlações em vários pontos além da cerâmica. Da comparação entre a fase do interior e os níveis que apresentam cerâmica nos sambaquis constatou-se o seguinte:

1) os sítios a céu aberto da fase Mucuri caracterizam-se, entre outros aspectos, por serem rasos ( $10 \mathrm{~cm}$ de espessura), atributo que deve estar associado à própria atividade de subsistência. É bem provável que a técnica agrícola empregada implicasse constante deslocamento para a exploração de novas terras. A cerâmica nos sítios identificados com a tradição Itaipu, embora pouco numerosa, pode ocorrer até $70 \mathrm{~cm}$ de profundidade, ${ }^{3}$ sete vezes mais profundo que a camada arqueológica dos sítios relacionados à fase Mucuri. Apesar das especificidades dos sambaquis no que se refere à própria composição, a profundidade em que foram encontrados os cacos indica uma permanência por demais prolongada num mesmo local, em comparação com os sítios do interior. Prática que, muito provavelmente, estaria em desacordo com os hábitos registrados para os grupos identificados com a fase Mucuri.

2) do relato de Ondemar Dias e Eliana Carvalho, pode-se depreender que os achados relacionados à fase Mucuri são abundantes e diversificados. O material cerâmico apresenta-se de tal ma-

(3) A profundidade aqui considerada refere-se à indicada para o sítio Corondó (Eliana Carvalho 1984: 65). neira em boas condições e em quantidade tão numerosa que foi possível estabelecer várias formas. Apenas nos níveis com cerâmica de alguns sítios pesquisados no litoral existe material adequado para determinar a forma dos vasilhames, em especial os sítios da baía da Ilha Grande estudados por Alfredo Mendonça de Souza (1977). No mais, as correlações baseiam-se sobretudo nas características dos fragmentos.

3) nos níveis com cerâmica dos sambaquis, não se tem notícia de enterramentos em urnas como os que ocorrem nos sítios identificados com a fase Mucuri, ou mesmo como os característicos do sítio Grande do Una. Existe apenas uma menção a um único enterramento relacionado à fase Una (Dias 1975: 9), porém, o autor ressalta nesse mesmo artigo que os limites entre a fase Una e Itaipu ainda não estão fixados.

4) a fase Jabaquara compartilha com a fase Mucuri o fato de ambas ocuparem abrigos, porém, no interior, os sítios cobertos têm função cerimonial, enquanto no litoral a presença da cerâmica caracterizadora da fase está associada a restos alimentares que se assemelham, na composição, aos sítios identificados como de tradição Macaé.

Constata-se que o único ponto em comum entrẻ os níveis que contêm cerâmica e os sítios identificados com a fase Mucuri é a cerâmica, e que todos os elementos que caracterizam os últimos níveis estão associados aos conjuntos denominados como da fase/tradição Macaé e da tradição Itaipu.

O mesmo tipo de observação pode ser feito em relação às evidências de cerâmica caracterizadas como de tradição Tupiguarani, que ocorre em sítios considerados como da fase/tradição Macaé e da tradição Itaipu. O trabalho de Lina Kneip, Monteiro e Seyferth (1980) sobre os sítio Três Vendas apresenta as características de um sítio Tupiguarani, ao passo que o estudo realizado no Zé Espinho exemplifica a presença de cerâmica e a manutenção de todas as outras características que definem o sítio nos primeiros momentos da ocupação.

A criação de uma fase pressupõe a identificação de uma determinada comunidade etnográfica, e é justamente isso que podemos supor que os pesquisadores estavam visando quando criaram as diferentes fases para definir os últimos níveis dos sítios caracterizados como de fase/tradição Macaé e tradição Itaipu. Ondemar Dias e Eliana Carvalho (1980: 53) estão particularmente afinados com esse pensamento, já que têm como premissa que a pre- 
sença de cerâmica existente sobre os sítios da tradição Itaipu indica a adaptação de grupos do interior ao litoral. Devido às diferenças aqui apontadas entre os níveis que apresentam cerâmica nos sítios do litoral e os sítios do interior, não me parece plausível supor que os últimos níveis dos sítios identificados como de tradição Macaé e tradição Itaipu tivessem sido ocupados por grupos ceramistas.

Reforça essa hipótese a constatação de que as características dos sítios - conteúdo e morfologia - foram mantidas. Caso tivessem sido de fato ocupados por diferentes grupos de ceramistas horticultores, sem dúvida os vestígios arqueológicos indicariam diferenças marcantes entre os sítios ocupados por grupos vinculados à tradição Una e à Tupiguarani, bem como estaria também registrada uma série de alterações decorrentes dos costumes desses grupos já tão bem caraçterizados na pré-história brasileira. A meu ver, a presença da cerâmica está indicando apenas contato entre os grupos pré-ceramistas e grupos ceramistas; caso houvesse relações de troca, todas as demais características poderiam ter sido mantidas.

É possível que Alfredo Mendonça de Souza (1981) estivesse pressupondo a existência de contato entre grupos identificados pelas diferentes fases quando propôs que a incidência da cerâmica indicaria a incorporação de um traço cultural. Essa idéia, todavia, não foi por ele desenvolvida. Por outro lado, não fica claro se a sua afirmação de que os grupos relacionados às fases litorâneas também se valiam de agricultura apóia-se na suposição de que os ocupantes dos sítios já dispunham de agricultura, ou se esse traço também teria sido incorporado.

Com base no exposto, reafirmo mais uma vez que não existem evidências conclusivas sobre a existência de atividade agrícola, embora esteja claro que os vegetais tiveram grande importância na vida dessa comunidades (cf. Tenório 1991). Considero tambẻm que a permanência em locais escolhidos para abastecer a população por meio de atividades voltadas para a exploração do mar nem sempre seria adequada às atividades agrícolas. Mais ainda, o fato de a cerâmica sèr encontrada desde $70 \mathrm{~cm}$ de profundidade indica uma prolongada permanência, e, caso houvesse a incorporação de práticas agrícolas, teria ocorrido uma continuada exploração do entorno dos sítios, que, a meu ver, não seria possível através da técnica aprendida junto com a cerâmica.

Embora não existam informações precisas sobre o tempo de formação dos sítios, é possível supor, com base nas datações do Corondó, que $70 \mathrm{~cm}$ de camada arqueológica poderiam ser acumulados em cerca de 400 anos. É fato que sítios diferentes têm rítmos diferentes de acumulação. Por exemplo, as datações provenientes do sambaqui da Ilha da Boa Vista indicam que $1,70 \mathrm{~m}$ foram acumulados em 370 anos (Gaspar, Barbosa \& Barbosa1994; Barbosa \& Gaspar, no prelo).

A subdivisão dos sítios com base no aparecimento da cerâmica não parece constituir uma estratégia profícua para o entendimento do processo de ocupação do Rio de Janeiro. Criar uma fase e vinculá-la a uma tradição diversa da que define os sítios pré-cerâmicos apenas estabelece uma separação mais radical entre os níveis que contêm cerâmica e o restante do sítio. Esse corte, a meu ver, não encontra respaldo nas características remanescentes dos sítios, que permanecem inalteradas. $\mathrm{Ou}$ seja, não parece adequado privilegiar a diferença a partir de um elemento numericamente pouco significativo, que é destacado, desconsiderando-se todos os demais elementos, que indicam continuidade.

Do meu ponto de vista, é a própria perspectiva de análise que impede a compreensão do fenômeno em toda a sua complexidade. $O$ esquema de fases e tradições não supera o impasse estabelecido com a permanência de todas as características e a incorporação de um novo material. Também não resolve a questão se a presença da cerâmica determina a criação de um novo tipo de sítio, ou se apenas acrescenta mais uma classe de material a ser descrito na arqueografia de sítio. As pesquisas coordenadas por Osvaldo Heredia, das quais participei ativamente, não se detiveram no estudo da ocorrência da cerâmica por consịiderar, de maneira equivocada, que esse material não se correlacionava com o objeto de investigação. Os estudos de Angela Buarque (1995), que ora estão sendo desenvolvidos, vêm exatamente suprir esta lacuna.

Acredito que somente a realização de um estudo detalhado, que considere de maneira articulada a distribuição espacial e temporal dos sítios com cerâmica, poderá avançar sobre o tema. Por ora, considero apenas que os dados não indicam que os sítios caracterizados até então como da fase/tradição Macaé e da tradição Itaipu foram ocupados por grupos ceramistas.

A cerâmica identificada com a tradição NeoBrasileira e variados restos do período colonial também ocorrem em sítios da fase/tradição Macaé e da tradição Itaipu, e sua presença aponta para outro 
tipo de problema. Alfredo Mendonça de Souza (1977: 68), ao estudar um conjunto de sítios nas proximidades da baía de Illha Grande, propôs a criação de um novo tipo de sítio que denominou "sambaqui de contato interétnico". São sítios rasos, com a espessura da camada arqueológica variando entre $30 \mathrm{e} 70 \mathrm{~cm}$, compostos de restos de moluscos e apresentando cerâmica da tradição Neo-Basileira em todos os níyeis, além de artefatos líticos, ósseos e sobre dentes. Um desses sítios - Trindade I -, descrito como "sambaqui em formação" (1977: 70 ), conta com grande quantidade de restos industriais pilhas, latas, etc..

Quanto a essa caracterização, não me parece apropriada a utilização do vocábulo sambaqui para definir locais de despejo de lixo de grupos contemporâneos, posto que o termo está intrinsicamente associado a espaço de habitação, bem como a local de sepultamento dos indivíduos que o construíram (Gaspar 1994/95). Esta correlação não está documentada nos sítios da baía da Ilha Grande.

A presença de cerâmica associada com a tradição Neo-Brasileira e diferentes restos atuais deve ser investigada a partir do estudo do sistema sóciocultural das populações recentes. As comunidades de pescadores muitas vezes ocupam as mesmas áreas em que estão localizados os sítios da fase/ tradição Macaé e da tradição Itaipu. Em Cabo Frio, os sítios localizados à margem do canal de Itajuru também apresentam cerâmica característica da tradição Neo-Brasileira e diferentes tipos de restos industriais nos últimos níveis. É possível que os locais em que se encontram os sítios da fase/tradição Macaé e da tradição Itaipu tenham sido particularmente escolhidos para o cultivo devido à fertilidade do solo resultante da concentração de matéria orgânica. Esta parece ser uma explicação plausível para a presença de restos coloniais e industriais nos últimos níveis de ocupação, e não que tenha havido contato entre os grupos relacionados com as tradições Macaé e Itaipu e a população do Brasil colônia. Existe a separá-los não apenas uma razoável distância temporal, mas um corte cultural decorrente da presença de grupos Tupi e Jê, que ocupavam a costa quando os europeus chegaram ao Brasil.

\section{Os esquemas explicativos}

Considero que os critérios classificatórios utilizados nos diferentes esquemas para identificar a fase/tradição Macaé e a tradição Itaipu não tềm valor operacional. Nenhum dos atributos assinalados pode ser considerado como elemento diferenciador, porque não é exclusivo de qualquer um dos conjuntos que foram construídos.

As categorias locacionais foram criadas a partir da observação do entorno ou mesmo da própria base dos sítios. Com isso, determinadas categorias que em alguns locais estão em oposição, em outros apresentam-se conjugadas, e portanto não são úteis à classificação.

A diferenciação a partir dos artefatos recuperados nos sítios também não fornece critérios definidores de conjuntos, pois se baseia em exemplares numericamente pouco expressivos, aprofundando os problemas amostrais já existentes. Alguns apresentam ainda dificuldades no tocante à determinação de função.

Apontadas as fragilidades dos atributos escolhidos, deve-se ressaltar ainda os problemas referentes ao próprio manejo dos critérios classificatórios. Em nenhum momento foi apresentada uma hierarquia de atributos. Na prática, os critérios são acionados de maneira alternada. Em algumas situações, a composição faunística constitui a diferença principal para definir os sítios, em outros, a localização parece ser determinante. Percebe-se que os esquemas de fases e tradições são usados apenas para ordenar em uma escala evolutiva, sem que sejam abordadas questões de organização social.

$\mathrm{Na}$ avaliação crítica até agora empreendida, foram sublinhadas contradições e inconsistências inerentes às propostas de interpretação da pré-histórica fluminense dentro dos esquemas de fase e tradição. Por tudo o que foi exposto, não me parece pertinente a subdivisão em fase/tradição Macaé e tradição Itaipu, e tampouco as subdivisões internas desses conjuntos. As diferenças apresentadas não são significativas e suficientes para que se aceite a divisão. Ao contrário, as semelhanças entre os testemunhos relacionados às fases e tradições são, na verdade, fortes indícios de que todos os sítios compartilhavam o mesmo sistema sócio-cultural. Ocupar a mesma área, muitas vezes a mesma praia e o mesmo local, apresentar indústrias e estruturas semelhantes população geneticamente análoga, compartilhar o hábito de acumular restos alimentares até formar montículos, habitar sobre esses restos e aí enterrar os mortos, seguindo padrão idêntico de enterramento, são traços que, a meu ver, compõem um conjunto que torna improcendente a se- 
paração dos sítios proposta nos esquemas explicativos.

É importante ressaltar ainda que os quadros construídos com base nos sistemas de fases e tradições apresentam problemas no que tange à sua própria concepção enquanto esquemas explicativos. Tais problemas estruturais moldam toda a percepção e concepção do próprio processo de ocupação pré-histórica. Já não mais se justifica a diferenciação feita inicialmente entre as linhas de pesquisa, pois o esquema de fases e tradições perpassou a maioria das pesquisas, e muitos que se dedicaram ao estudo de sítios isolados definiram o seu objeto de estudo a partir desse esquema.

O problema que se coloca são os próprios quadros interpretativos. A questão mais grave observada refere-se à correlação mecânica de dados obtidos a partir dos vestígios arqueológicos e observações de cunho sociológico. Não se pode ignorar que os testemunhos das sociedades pré-históricas recuperados resultam de inúmeros processos que incluem atividades afetas ao próprio grupo em estudo (processo de descarte), bem como processos naturais seletivos e culturais relacionados a outros sistemas de ocupação, e portanto que os vestígios não devem ser considerados como um espelho no qual se pode ver refletido o passado. Mais ainda, mesmo se o trabalho do arqueólogo se desenvolvesse em condições excelentes de preservação, as evidências abundantes que porventura se apresentassem ainda teriam de ser interpretadas à luz de teorias compatíveis.

Percebe-se que, na produção selecionada, a ênfase é dada ao estudo dos objetos recuperados, que são descritos, medidos, pesados e comparados entre si, mas, em última análise, não são percebidos como um documento que permite acesso a uma determinada realidade sociológica. É a conjugação das semelhanças e diferenças dos artefatos, dos restos faunísticos, dos pacotes estratigráficos etc.. que compõe os conjuntos. Como resultado, os quadros elaborados ficam ao sabor dos dados empíricos, dados esses que são infinitos e podem ser ampliados em cada nova pesquisa, e cuja incorporação provoca uma série de redefinições tanto de critérios como de conjuntos. Cria-se um novo conjunto, uma nova fase, ou desloca-se uma já existente em determinada direção, ou em outra contrária, acrescentandose, dessa forma, mais uma contribuição ao esquema.

$\mathrm{Na}$ realidade, coexistem duas tendências. De um lado, investe-se exageradamente no estudo dos artefatos e evidências materiais, sem maiores preo- cupações com o seu papel no sistema sócio-cultural que o produziu. De outro, considera-se esse mesmo objeto como um indicador direto e seguro de certos domínios da sociedade cujos vestígios se preservaram. E embora praticamente nada tenha sido aventado sobre a organização social do grupo estudado, admite-se, por exemplo, que os restos faunísticos refletem a economia do grupo.

Como decorrência do excessivo empirismo, o tópico relativo à organização social que os arqueólogos mais se dedicaram a estudar foi a economia, restringindo-se, porém, direcionados pela própria perspectiva, ao aspecto da dieta alimentar. Muitas vezes, a dieta estabelecida revelou-se tão deficitária que não possibilitaria sequer a sobrevivência dos indivíduos (Mello \& Alvim, sd).

O ponto crítico prevalente nos esquemas propostos, todavia, é a ausência de uma noção sistêmica. Fica patente a visão parcial de sociedade, sobretudo quando se trata de contato entre grupos que se acredita corresponderem às diferentes fases e tradições. A ausência de uma perspectiva estruturadora de organização social impossibilita que sejam inferidas, em toda a sua complexidade, as relações entre diferentes grupos. Isso fica particularmente evidente nos estudos de sítios, quando se admite o recorte empírico dado pelo próprio contorno do sítio, chegando-se mesmo, em alguns casos, a imprimir valor sociológico à área de escavação ou a determinada etapa de pesquisa. $O$ sítio é a unidade de pesquisa, recorte que o torna deslocado no tempo e no espaço, ou é correlacionado a outros testemunhos a partir de atributos que podem ser questionados, não se considerando imprescindíveis as relações sociais entre grupos que habitaram os diferentes locais. As correlações, quando feitas, restringem-se a aspectos da cultura material.

Os sistemas mais gerais recaem no mesmo equívoco, até porque se nutrem de informações advindas das pesquisas particularistas. $E$ ainda que enfatizem as relações entre os sítios ao agrupá-los em categorias fases, tradições, estágios , os conjuntos formados não incorporam uma dimensão sistêmica.

A maneira como as pesquisas relacionadas aos esquemas de fase e tradição são elaboradas pressupõe o estudo de partes sem uma visão articulada do conjunto. Esse princípio torna possível a identificação de uma fase ou complexo cultural com base em apenas cinco sítios espalhados por todo o litoral do Rio de Janeiro. O conjunto que essa linha de pesquisa se propõe a construir, a partir da premissa 
de que as partes isoladas podem representar o todo, constitui apenas um somatório de características. Na prática, o esquema de classificação se prende ao exame de classes de artefatos (cerâmica, por exemplo) produzindo uma interpretação parcial. $O$ resultado das duas vertentes de pesquisa é uma vi'são fragmentária da órganização social dos grupos estudados.

O outro problema diz respeito à relação entre cultura e natureza, que, para a arqueologia, refletese na relação sítio e ambiente. Nos trabalhos vinculados à perspectiva organicista, os fatores ambientais têm prerrogativa conformadora dos fenômenos culturais. Já na arqueografia de sítios isolados, sítio e ambiente são domínios independentes, reunidos apenas na caracterização da dieta alimentar. Em alguns casos, o ambiente é tão-somente o lugar onde o sítio está localizado.

As duas perspectivas - natureza e cultura como domínios isolados, ou natureza prevalecendo sobre a cultura - não possibilitam uma análise da interação sítio e ambiente em maior profundidade.

Em resumo, a classificação proposta para os sítios pré-cerâmicos apresenta-se, a meu ver, pouco fundamentada, e os próprios esquemas interpretativos, bastante problemáticos. A meta que perpassa as análises é ordenar os diferentes sítios numa escala temporal e atribuir às transformações ambientais, tanto temporais como espaciais, o papel gerador das mudanças sociais.

\section{Quadro arqueológico}

As observações restritivas não se aplicam à seriedade com que esses trabalhos foram desenvolvidos, nem à quantidade de informações que forneceram. É preciso deixar claro que se trata do primeiro esquema interpretativo elaborado e tem o mérito inegável de ser um marco no conhecimento da préhistória do Rio de Janeiro, representando um ponto de partida para toda e qualquer pesquisa.

A partir das informações disponíveis, tornase possível retomar alguns dados e reelaborar determinadas hipóteses sobre a ocupação do litoral. Pouco se sabe sobre a origem dos primeiros grupos que começaram a construir os sambaquis. Permanecem dúvidas se as datações mais aṇiigas representam de fato os primeiros sítios, ou se estes teriam sido destruídos devido à subida do nível do mar.

Considerando todas as datações existentes para sambaquis brasileiros, constata-se uma maior antigüidade no estado do Pará sambaqui de Taperinha (Roosevelt et alii 1991). Não estou considerando a datação de Maratuá, São Paulo, de $7803 \pm 1300$ AP (Laming-Emperaire apud Kneip 1976: 96), e sim a apresentada por Uchôa (1978/79/80: 25), que atribui a antigüidade de $3865 \pm 55$ AP, de Camboinhas, Rio de Janeiro, de $7958 \pm 224$ AP, e de Capelinha, São Paulo, $10500 \pm 1500 \mathrm{AP}$.

Segundo análise de datações disponíveis (Gaspar, no prelo), a data do sambaqui de Capelinha-SP (10500 $\pm 1500 \mathrm{AP})$, a mais antiga de todas, está confirmada por uma outra de $9890 \pm 1500$ anos, muito embora esteja totalmente isolada em relação aos outros testemunhos do mesmo estado. Barreto (1988: 213), estudiosa dos sambaquis đả região onde está o Capelinha, considera que é possível que estas datações não correspondam de fato à ocupação dos grupos ligados aos concheiros, pois o sítio apresenta sobreposição de vestígios de grupos culturalmente distintos.

A datação de Camboinhas-RJ $(7958 \pm 224)$ já foi alvo de críticas de geomorfólogos e de geólogos que a consideram de uma antigüidade improvável, porém, a equipe que o estudou, após novas investigações, propõe que é procedente (Kneip, Ferreira \& Muehe 1994). Como a datação envolve uma reflexão sobre a idade da formação dos cordões litorâneos, tema sobre que não estou apta a opinar, acho prudente aguardar o desenrolar do debate. A data de Camboinhas apresenta um certo isolamento em relação à subseqüente do Estado ( $5520 \pm 120$, Forte) e em relação às outras disponíveis para o próprio sítio (ver Tabela e Gráfico 1).

A datação de Taperinha certamente está confirmada pela seqüência cronológica de 11 datações que abrange o período de 7090 até 5705 anos (Roosevelt et al. 1991: 63).

As datas dos sambaquis do Norte foram incorporados nessa análise porque considero que os sambaquis das diferentes regiões brasileiras compartilham de características estruturadoras. A constatação de que os construtores de sambaquis associavam, num mesmo espaço, o local de moradia, de sepultamento dos mortos e de descarte de bens e de restos alimentares é um forte indicador de que eles integravam um mesmo sistema sócio-cultural (cf. Gaspar 1994/95). Se o Norte foi, de fato, a região de dispersão desta população, e se as datações subseqüentes estão no estado do Paraná, ainda é preciso que se realizem muitos estudos para se 
entender todo o processo de ocupação dos pescadores, coletores e caçadores.

No Sul do país, no Paraná, teriam partido dois eixos de ocupação seguindo a costa, nas direções Norte e Sul. Esse movimento migratório foi proposto por Schmitz (1991) e é amplamente aceito pelos pesquisadores. A leva migratória que seguiu para o Norte teria alcançado o estado do Rio de Janeiro.

As datações disponíveis para a região da pesquisa indicam que, desde 5520 (Kneip 1980), os sítios já estavam sendo ocupados. Pelo menos durante 4000 anos a região esteve habitada por grupos que exploravam intensamente os recursos marinhos. Os vestígios alimentares indicam um padrão de subsistência fundamentado na pesca e na coleta de moluscos, e complementado pelos recursos terrestres que eram obtidos por meio da caça de pequenos animais e da coleta de vegetais.

A presença de abundantes restos esqueletais de peixe, alguns de grande porte, e que têm como habitat águas profundas (Kneip, Magalhães, Mello $\&$ Correa 1989: 126), sugere que os grupos eram canoeiros. A implantação dos sítios e sua distribuição reforçam essa idéia. Esses grupos deviam fazer uso de rede de pesca, pois as inúmeras carapaças de moluscos de pequenas dimensões - Neritina virginea (Linnaeus 1758) - e Bulla striata (Bruguiere 1792) encontradas intactas nos sítios, suscitam a hipótese de que sejam decorrentes da utilização de algum tipo de arrasto.

As estruturas habitacionais identificadas em várias pesquisas indicam a ocupação desses montes durante a sua própria construção. Seus mortos eram enterrados nesse mesmo espaço, e a descoberta de um esqueleto flechado (Kneip 1987: 162) indica que existiam disputas e conflitos entre os grupos.
Esse padrão de assentamento manteve-se com certa estabilidade durante 4000 anos e perdurou até o contato com grupos ceramistas. É possível supor que os grupos identificados com as tradições Una e Tupiguarani entraram em contato com os pré-ceramistas, inicialmente, sem ocupar a região, o que só veio a ocorrer em período posterior. A datação obtida para o sítio Grande do Una - Rio Una I - indica que, por volta de $1060 \pm 90 \mathrm{AP}$, grupos identificados com a fase Una estariam compartilhando o mesmo espaço com os grupos residentes. A datação obtida para Morro Grande (Buarque 1995) indica que os Tupinambá já estavam na região desde $1740 \pm 90 \mathrm{AP}$. Nesse período, é provável que pelo menos alguns sítios pré-cerâmicos ainda estivessem ativos (ver quadro de datações). A disputa por território e a superioridade tecnológica dos ceramistas devem ter desarticulado o sistema sócio-cultural pré-cerâmico, impondo integração no novo sistema e/ou migração para o interior (cf. Neves 1988: 52, para o litoral sul). Os grupos pré-ceramistas, caso tenham migrado, devem ter seguido o litoral, já que não existe qualquer evidência arqueológica de sua presença em áreas mais interioranas.

\section{Agradecimentos}

Agradeço a orientação instigante de Ulpiano Bezerra de Meneses na elaboração desse capítulo durante a confecção de minha tese de doutorado, a leitura atenta de Lina Kneip e de Angela Buarque. Agradeço à Sheila Mendonça de Souza as sugestões e à Márcia Barbosa a preparação do gráfico e da tabela.

\section{Referências bibliográficas}

AB'SABER, A.N.

1978/ Paleo-clima e paleo-ecologia. P.E. Schmitz, et al

79/80 (Eds.). Temas de Arqueologia Brasileira, 1, Anuário de Divulgação Científica, Instituto Goiano de Pré-História, Goiânia: 33-50.

AZEVEDO, J.A.A.; CARVALHO, E.T.; DIAS JR, O.F.

1981/82Análise preliminar de arqueofauna do RJ-JC-64, Corondó, fauna de cordados. Arquivos do Museu de História Natural. Universidade Federal de Minas Gerais, Belo Horizonte, 6-7: 157-160.

BACKHEUSER, E. A.

1919 Os sambaquis do Distrito Federal. Revista Didá- tica da Escola Politechnica, Rio de Janeiro, 18: 1-30.

BARBOSA, M.; GASPAR,M.D.

prelo El processo de formación des sambaqui Ilha da Boa Vista I, Rio de Janeiro - Analisis comportamental de la cadena de actividades. Anais do simposio Arqueologia de las "Tierras Bajas" República Oriental del Uruguay.

BARBOSA, M.; GASPAR, M.D.; BARBOSA, D.R.

1994 A organização espacial das estruturas habitacionais e distribuição dos artefatos no sítio Ilha da Boa Vista I, Cabo Frio, RJ. Revista do $\mathrm{Mu}$ - 
seu de Arqueologia e Etnologia, Universidade de São Paulo, São Paulo, 4: 31-38.

\section{BARRETO, C.N.G.B.}

1988 A ocupação do vale do Ribeira do Iguape, SP: os sítios concheiros do médio curso. Dissertação de Mestrado. Faculdade de Filosofia, Letras e Ciências Humanas da Universidade de São Paulo. São Paulo.

BELTRÃO, M.C.M.C.

1978 Pré-História do Estado do Rio de Janeiro. Rio de Janeiro, Forense Universitária, 276 p, il.

BELTRÃO, M.C.M.C.; KNEIP. L.M.

1967 Arqueologia e geomorfologia; tentativa de uma abordagem interdisciplinar. Boletim Carioca de Geografia, Rio de Janeiro, 18: 1-16.

1969 Escavaçōes estatigráficas no Estado da Guanabara. Simpósio de Arqueologia da Área do Prata, III. Pesquisas, S. Antropologia, São Leopoldo, Anais, 20: 101-112.

BELTRÃO, M.C.M.C.; HEREDIA, O.R.; NEME, S.M.N.

1978 Coletores de moluscos litorâneos e sua adaptação ambiental: o sambaqui de Sernambetiba. Anais do Museu de História Natural, Universidade Federal de Minas Gerais, Belo Horizonte, 3: 97-115.

BELTRÃO, M.C.M.C.; HEREDIA, O.R.; RABELLO, A.M.C.; PEREZ, R.A.R.

1981/82 Pesquisas arqueológicas no sambaqui de Sernambetiba. Arquivos do Museu de História Natural. Universidade Federal de Minas Gerais, Belo Horizonte, 6/7: 145-156.

BINFORD, L.R.

1968 Social determinants of group size. R.B. Lee; I. Devore (Eds.) Man the Hunter. Aldine Plublishing Company, Chicago: 155-156.

BUARQUE, A.

1995 A aldeia tupinambá de Morro Grande. Reunião Científica da Sociedade de Arqueologia Brasileira, VIII, Porto Alegre. Resumos.

CANCIO, F.

1987 Ocorrência de cerâmica na camada superior do sambaqui Zé Espinho. L.M Kneip (Ed.) Coletores e Pescadores Pré-Históricos de Guaratiba, Rio de Janeiro. MN/UFRJ, EDUIFF, Rio de Janeiro: 165-184.

CARVALHO, E.T.

1988 O sítio Duna Grande de Itaipu. Uma contribuição. Revista de Arqueologia, Sociedade de Arqueologia Brasileira, Rio de Janeiro, 5(1): 119128.

CHMITZ, P.I.; WÜST, I; COPÉ, S.M.; THIES, U.M.E.

1982 A arqueologia do centro-sul de Goiás. Pesquisas, Instituto Anchietano de Pesquisas, RS, 33.

CUNHA, F.L.S.; FRANCISCO, B.H.R.

1981 Geologia de Itaipu. Kneip, L.M. et al. (Eds.) Pesquisas Arqueológicas no Litoral de Itaipu, Niterói, $R J$. Rio de Janeiro, Luna, 174 p, il: 1526.

CUNHA, F.L.S.; MAGALHÃES, R.M.M.; GARCIA, S.

1977 Vertebrados do sambaqui do Forte. Kneip, L.
(Org.) Pescadores e Coletores Pré-Históricos do Litoral de Cabo Frio. Coleção Museu Paulista, S.Arqueologia, SãoPaulo, 5: 143-150.

DE BLASIS, P.; AFONSO, $M$.

1996 Indicadores de complexidade nos grandes sambaquis do litoral sul. Resumos do simposio Arqueologia de las "Tierras Bajas" República Oriental del Uruguay.

DIAS JÚNIOR, O.F.

1969 A fase Itaipu, sítios sobre dunas no Estado do Rio de Janeiro. Simpósio de Arqueologia da Área do Prata, III. Pesquisas, São Leopoldo, Anais, 20: 5-12.

1975 Pesquisas arqueológicas no Sudeste Brasileiro. Boletim do Instituto de Arqueologia Brasilei$r a$, S. Especial, Rio de Janeiro, 1: 3-21.

1976/77Evolução da cultura em Minas Gerais e no Rio de Janeiro. Schmitz, P.E. et al. (Eds.) Temas de Arqueologia Brasileira, Anuário de Divulgação Científica, Instituto Goiano de Pré-História, Goiânia, 3: 112-130.

1987 Pré-História e arqueologia da região sudeste do Brasil. A pesquisa do passado. Boletim do Instituto de Arqueologia Brasileira, Rio de Janeiro: 155-164.

1978/ Sinópse do "Arcaico" do litoral de São Paulo.

79/80 P.I. Schmitz; A.S. Barbosa; M.B Ribeiro (Eds.) Temas de Arqueologia Brasileira 3. Anuário de Divulgação Científica Instituto Goiano de PréHistória e Antropologia, Univesidade Católica de Góias, Goiânia, 7: 15-32.

s/d O pré-cerâmico no Rio de Janeiro. Arqueologia. Catálogo. CEA-ETP-IAB. Rio de Janeiro, 4 p.

DIAS JUNIOR, O.F; CARVALHO, E.

1980 A pré-história da serra fluminense e a utilização das grutas no estado do Rio de Janeiro. Pesquisas, Instituto Anchietano de Pesquisa, São Leopoldo, 31: 43-86.

1983/84 A fase Itaipu, RJ. Novas considerações. Arquivos do Museu de História Natural, Universidade Federal de Minas Gerais, Belo Horizonte, 8/ 9: 95-106.

1990 Tradição Itaipu (RJ) - Discussão de tópicos a proposta de um modelo teórico. Reunião Científica da Sociedade de Arqueologia Brasileira, V, Santa Cruz do Sul. Anais. Revista do Centro de Estudos e Pesquisas Arqueológicas, Santa Cruz do Sul: 157-166.

FERNANDES, F

1963 Organização Social dos Tupinambá. São Paulo, Difusão Européia do Livro.

FIGUTI, L.

1993 O homem pré-histórico, o molusco e o sambaqui: considerações sobre a subsistência dos povos sambaquianos. Revista do Museu de Arqueologia e Etnologia, Universidade de São Paulo, São Paulo, 3: 67-80.

1995 Amostragem arqueofaunística em sítios portadores de conchas. Simpósio de Arqueologia da Região Sudeste, II, São Paulo. Resumos. Museu 
de Arqueologia e Etnologia, Universidade de São Paulo.

FRANCO, T.C.B.; GASPAR, M.D.

1992 O sítio arqueológico Salinas Peroano. Reunião Científica da Sociedade de Arqueologia Brasileira, VI, Rio de Janeiro. Anais, 1: 162-171.

\section{GASPAR, M.D}

1991 Aspectos da Organização de um Grupo de Pescadores, Coletores e Caçadores: Região Compreendida entre a Ilha Grande e o Delta do Paraíba do Sul, Estado do Rio de Janeiro. Tese de Doutoramento, Departamento de Antropologia, Faculdade de Filosofia, Letras e Ciências Humanas, Universidade de São Paulo. São Paulo. 362 p., il.

1994/95Espaço, rito e identidade pré-histórica. Reunião Científica da Sociedade de Arqueologia Brasileira, VII, João Pessoa. Anais. Revista de Arqueologia, São Paulo, 8(2): 221-237, il.

1995 Datações, construção de sambaquis e identidade social dos pescadores, caçadores e coletores. Anais da VIII Reunião da Sociedade de Arqueologia Brasileira.

prelo a Análise das datações radiocarbônicas dos sítios de pescadores, coletores e caçadores. Boletim do Museu Goeldi.

prelo b Construcción de "sambaquis" y ocupación del territorio brasileño por pescadores, recolectores y cazadores. Anais do simposio Arqueologia de las "Tierras Bajas" República Oriental del Uruguay.

GASPAR, M.D. \& DE BLASIS, P.

1992 Construção de sambaqui. Reunião Científica da Sociedade de Arqueologia Brasileira, VI, Rio de Janeiro. Anais, 2: 811-820.

GASPAR, M.D.; BARBOSA, D.: BARBOSA, M.

1994 Análise do processo cognitivo de construção do sambaqui da Ilha da Boa Vista I. Revista CLIO, Universidade Federal de Pernambuco, Recife, I(10): 103-123.

GUERRA, A.T.

1955 Notas a propósito de depósitos conchíferos de São Lourenço, Boa Vista e Chácara Vintém (Niterói, Estado do Rio de Janeiro). Boletim Geográfico, Rio de Janeiro, 8(126): 305-309.

HASSAN, F.

1978 Demography archaeology. M. Schiffer (Org.) Advances in Archaeology Method and Theory, vol I. Academic Press: 49-103.

HEREDIA, O.R.

1978 Cazadores-recolectores-pescadores prehistóricos en el Estado do Rio de Janeiro (Explotacions estacional o ciclica de los recursos naturales en diferentes microambientes). Projeto de pesquisa, Fundação Ford, Rio de Janeiro. 16 p. (mimeo.).

1983 O aproveitamento ambiental pelas populações préhistóricas do Estado do Rio de Janeiro. Relatório de pesquisa. FINEP/MN/FUJB. Rio de Janeiro (mimeo.).
1984 O aproveitamento ambiental pelas populações préhistóricas do Estado do Rio de Janeiro. Relatório de pesquisa. FINEP/MN/FUJB. Rio de Janeiro (mimeo.).

1985 O aproveitamento ambiental pelas populações préhistóricas do Estado do Rio de Janeiro. Relatório de pesquisa. FINEP/MN/FUJB. Rio de Janeiro (mimeo.).

1986 O aproveitamento ambiental pelas populações préhistóricas do Estado do Rio de Janeiro. Relatório de pesquisa. FINEP/MN/FUJB. Rio de Janeiro. (mimeo.)

1987 O aproveitamento ambiental pelas populações préhistóricas do Estado do Rio de Janeiro. Relatório de pesquisa. FINEP/MN/FUJB. Rio de Janeiro. (mimeo.)

HEREDIA, O.R.; BELTRÃO, M.C.M.C.; OLIVEIRA, M.D.G.; GATTI, M.P.

1981/82 Pesquisas arqueológicas no sambaqui do Amorins. Arquivos do Museu de História Natural, Universidade Federal de Minas Gerais, Belo Horizonte, 6-7: 175-188,

HEREDIA, O.R.; GASPAR, M.D.; GATTI, M.P.; FRANCO, T.C.B.

1983 Pesquisas arqueológicas no sítio Salinas Peroano. Reunião Científica da Sociedade de Arqueologia Brasileira, II, Belo Horizonte. (mimeo.).

HEREDIA,O.R.; GASPAR, M.D.; SETTE,B.; BULCÃO,S.

s/d Resultados preliminares das escavações arqueológicas no sítio Boca da Barra. (mimeo).

HEREDIA, O.R.; GATTI, M.P; GASPAR, M.D.; BUARQUE, A.M.G.

1984 Assentamentos pré-históricos nas ilhas do litoral centro-sul brasileiro: o sítio Guaiba (Mangaratiba-RJ). Revista de Arqueologia, Rio de Janeiro, 2(1): 13-31.

HEREDIA, O.R.; GATTI, M.P; GASPAR, M.D.; SETTE, B.D.; BULCÃO, S.M.R.

1985 Resultados preliminares das escavações arqueológicas no sítio Boca da Barra, RJ. Reunião Científica da Sociedade de Arqueologia Brasileira, III, Goiânia. (mimeo.).

HEREDIA,O.R.; GASPAR, M.D.; SCARAMELLA, G.; FRANCO, T.C.B.

1985 Escavações arqueológicas no sítio Salinas Peroano, Cabo Frio-RJ. Reunião Científica da Sociedade de Arqueologia Brasileira, III, Goiânia. (mimeo.).

HEREDIA, O.R.; TENÓRIO, M.C.; GASPAR, M.D.; BUARQUE, A.M.G.

1989 Environment explotation by prehistorical population of Brazil. American Society of Civil Engineers. New York: 230-239.

KNEIP, L.M.

1976 Sambaqui do Forte - identificação espacial das atividades humanas e sua implicações (Cabo Frio, RJ, Brasil). Coleção do Museu Paulista, S. Arqueologia, São Paulo, 2: 81-142.

1977 Pescadores e coletores pré-históricos do litoral de Cabo Frio, RJ. Coleção Museu Paulista, São Paulo, 5: 7-169. 
1980 A sequiência cultural do sambaqui do Forte-Cabo Frio, Rio de Janeiro. Schmitz, P.I. (Ed.) Pesquisas, S. Antropologia. Estudos de Arqueologia e Pré-História Brasileira, São Leopoldo, 31 : 87-100.

1987 Coletores e Pescadores Pré-Históricos de Guaratiba, Rio de Janeiro. Rio de Janeiro, EDUFF/ Museu Nacional, 257 p., il.(Série Livro 5).

1992 As habitações 1 e 2 do sambaqui da Pontinha (Saquarema, RJ). Reunião Científica da Sociedade de Arqueologia Brasileira, VI, Rio de Janeiro, Anais 2: 730-37.

1994 Cultura material e subsistência das populações pré-históricas de Saquarema, RJ. Documentos de Trabalho, S.Arqueologia, Museu Nacional/ Universidade Federal do Rio de Janeiro, Rio de Janeiro, 2, $120 \mathrm{p}$.

KNEIP, L.; FEREIRA, A.M.M. \& MUEHE, D.

1994 Contribuição ao estudo da Pré-história e do Paleoambiente da região entre Cabo Frio e Guaratiba, RJ. M.C. Tenório; T.C. Franco (Orgs.) I Seminário de Implantação da Temática Pré-História Brasileira no Ensino de $1^{\circ}, 2^{\circ}$ e $3^{\circ}$ graus. Rio de Janeiro, 146 p. Anais. EDUFRJ/MN: 127131.

KNEIP, L.M.; MACHADO, L.M.C.

1993 Os ritos funerários das populações pré-históricas de Saquarema, RJ: sambaquis da Beirada, Moa e Pontinha. Documento de Trabalho, S. Arqueologia, 1 , Rio de Janeiro. Museu Nacional/Universidade Federal do Rio de Janeiro, 76 p., il.

KNEIP, L.M.; PALLESTRINI, L.

1987 Arqueologia: estatigrafia, cronologia e estruturas do sambaqui do Zé do Espinho. L.M. Kneip (Org.) Coletores e Pescadores Pré-históricos de Guaratiba - Rio de Janeiro. Rio de Janeiro, EDUFF/Museu Nacional, 257 p., il: 89 -141.

KNEIP, L.M.; CANCRIO, F.; RODRIGUES, B.H.

1990 O Sambaqui da Beira da (Saquarema - RJ). Aspectos culturais e paleoambientais. Revista de Arqueologia. Sociedade de Arqueologia Brasileira, Rio de Janeiro, 5(1): 41-55.

KNEIP, L.M.; COELHO, A.C.S.; CUNHA, F.L.S.; MELLO, E.M.B.

1975b O sambaqui do Forte, Cabo Frio, Rio de Janeiro, Brasil. Interrelationship between molluscs vertebrates and archaeological materials. Boletim $\mathrm{Pa}$ ranaense de Geociências, Curitiba, 33: 49-50.

KNEIP, L.M.; COELHO, A.C.S.; CUNHA, F.L.S.; MELLO, E.M.B.

1975a Informações preliminares sobre a arqueologia e fauna do Sambaqui do Forte, Estado do Rio de Janeiro, Brasil. Revista do Museu Paulista, São Paulo, 22: 89-108.

KNEIP, L.M.; MAGALHÃES, R.M.M.; MELLO, E.M.B.; CORRÊA, M.M.G.

1989 O sambaqui da Beirada (Saquarema-RJ). Dados culturais, faunísticos, e cronológicos. Congresso Brasileiro de Paleontologia, IX, Curitiba. Anais: 651-666.
KNEIP, L.M.; PALLESTRINI, L.; CANCRIO, F.; MACHADO, L.M.C.

1991 As estruturas e suas interrelações em sítios de pescadores-coletores pré-históricos do litoral de Saquarema, RJ. Boletim do Instituto de Arqueologia Brasileira, S. Ensaios, Rio de Janeiro, 5, 42p.

KNEIP, L.M.; PALLESTRINI, L.; CUNHA, F.L.S.

1981 Pesquisas Arqueológicas no Litoral de Itaipu, Niterói, Rio de Janeiro. Rio de Janeiro, Luna, $174 \mathrm{p}$.

KNEIP, L.; MONTEIRO, A.M.F.; SEYFERTH, G.

1980 A aldeia pré-histórica de Três Vendas, Araruama, Estado do Rio de Janeiro. Revista do Museu Paulista, Nova Série, São Paulo, XXVII: 283-338.

LIMA, T.A.

1991 Dos Mariscos aos Peixes: um Estudo Zooarqueológico de Mudança de Subsistência na Pré-História do Rio de Janeiro. Tese de Doutoramento. Faculdade de Filosofia, Letras e Ciências Humanas, Universidade de São Paulo, São Paulo.

LIMA, T.A.; SILVA, R.C.P.

1984 Zooarqueologia: alguns resultados para a préhistória da ilha de Santana. Revista de Arqueologia, Sociedade de Arqueologia Brasileira, Belém, 2(2): 10-40.

LIMA, T.A.; MELLO, E.M.B.; SILVA, R.C.P.

1986 Analyses of molluscan remains from the Ilha de Santana, Macaé, Brazil. Journal of Field Archaeology, 13: 83-97.

MACHADO, L.C.; KNEIP, L.M.

1994 Padrões dentários, dieta e subsistência das populações dos sambaquis de Saquarema, RJ. Reunião Científica da Sociedade de Arqueologia Brasileira., VII, João Pessoa. Anais. Revista de Arqueologia, Sociedade de Arqueologia Brasileira, São Paulo, 8(1): 45-57.

MACHADO, L.C.

1984 Análise dos remanescentes ósseos humanos do sítio arqueológico Corondó, RJ. Aspectos biológicos e culturais. Série Monografias, 1, Instituto de Arqueologia Brasileira, Rio de Janeiro, $425 p$.

MACHADO, L.C.

1994 Possível associação entre idade, patologia esqueletal e tratamento funerário diferenciado. Estudo de caso em população horticultora préhistórica, sítio do Caju, Campos, Estado do Rio de Janeiro. III Congresso Latino Americano de Antropologia Biológica e II Reunião da Sociedade Brasileira de Paleopatologia. Rio de Janeiro: 27

MACHADO, L.M.; PONS, E.; SILVA, L

1989a Os sítios Massambaba (RJ-JC-56) e Boqueirão (RJ-JC-57), Arraial do Cabo - Rio de Janeiro. Os padrões de sepultamento. Reunião Científica da Sociedade de Arqueologia Brasileira, IV, Santos. Anais. Dédalo, Publicações Avulsas, São Paulo, 1: 447-454. 
1989b Adaptação bio-cultural no litoral fluminense: os restos ósseos humanos de dois sítios arqueológicos de Arraial do Cabo Rio de Janeiro. Reunião Científica da Sociedade de Arqueologia Brasileira, IV, Santos. Anais. Dédalo, Publicações Avulsas, São Paulo, 1: 429-446.

MAUSS,M.

1974 Ensaio sobre as variações sazoneiras das sociedades esquimó. Antropologia e Sociologia, São Paulo, EPU/EDUSP: 237-331.

MEGGERS, B.J.; EVANS, C.

1985 A utilização das sequências cerâmicas seriadas para inferir comportamento social. Boletim, Série Ensaios. Instituto de Arqueologia Brasileira, Rio de Janeiro, 30.

1970 Como interpretar a linguagem da cerâmica. Manual para arqueológos. Smithsonian Institution, Washington.

MELLO, E.M.B.; SOUZA, A.M.

1977 O Sambaqui de Saracuruna.Nheengatu, Instituto Superior de Cultura Brasileira, Rio de Janeiro, $1(1)$ : 43-58.

MELLO E ALVIM, M.C.

1977 Sambaquis. Revista da Atualidade Indígena, Brasília, l(6), set/out.

s/d Estudo morfológico da população do Sambaqui de Cabeçuda (Laguna, Santa Catarina). Anais da Academia Brasileira de Ciências, Rio de Janeiro, 39(3/4): 549.

MENDONÇA DE SOUZA, A.A.C.

1977 Pré-história de Parati. Nheengatu. Caderno Brasileiro de Arqueologia Indígena, Instituto Superior de Cultura Brasileira, Rio de Janeiro, I(2): 47-90.

1981 Pré-História Fluminense. Instituto Estadual do Patrimônio Cultural e Secretaria Estadual de Educação e Cultura, Rio de Janeiro, 87 p.

MENDONÇA DE SOUZA, S.M.F.; MENDONÇA DE SOUZA, A.A.C.

1983 Tentativa de interpretação paleoecológica do sambaqui do rio das Pedrinhas-Magé-RJ. Instituto Superior de Cultura Brasileira, Rio de Janeiro.

MENDONÇA DE SOUZA, S.M.F.; SANTOS, R.S.; SCHRAM, C.S.; MIRANDA, C.C.

1983/84Estudos de paleonutrição em sítios-sobre-dunas da fase Itaipu-RJ. Arquivos do Museu de História Natural, Universidade Federal de Minas Gerais, Belo Horizonte, 8/9: 107-120.

MESSIAS, T.T.

1977 Estudo morfológico da população do Sambaqui do Forte. L. Kneip (Org.) Pescadores e Recoletores Pré-Históricos do Litoral de Cabo Frio. São Paulo, Ed. Fundo de Pesquisa do Museu Paulista, 169 p., il. (Série Arqueologia, 5): 165 167.

MEZZALIRA, $S$.

1946b Tentativa de correlação entre as nomenclaturas científicas e populares dos moluscos encontrados nos Sambaquis brasileiros. OIGG, São Paulo, 4(3): $272-80$, jul./set.
NEVES, W.A.

1988 Paleogenética dos grupos pré-históricos do litoral sul do Brasil (Paraná e Santa Catarina). Pesquisas, S.Antropologia, São Leopoldo, 43, 178p.

NEVES, W.A.; UNGER, P.; SCARAMUZZA, C.A.M.

1984 Incidência de cáries e padrões de subsistências no litoral norte de Santa Catarina, Brasil. Revista de Pré-História, Instituto de Pré-História, Universidade de São Paulo, São Paulo, 4, 49p.

PALLESTRINI, L.; CHIARA, F.

1981 O material lítico. L. Kneip et al. (Orgs.) Pesquisas Arqueológicas no litoral de Itaipu, Niterói, $R J$. Rio de Janeiro, Cia de Desenvolvimento Territorial: 71-93.

PANOFF,M.; PERRIN,M.

1973 Dictionnaire de l'ethnologie. Paris, Payot.

PEROTA, C.

1974 Resultados preliminares da região central do Estado do Espírito Santo. Boletim do Museu Paraense Emilio Goeldi. Publicações Avulsas, Belém, 26: 127-140. PRONAPA 5. Resultados preliminares do quinto ano, 1969-70.

PROUS, A.

1977 Les sculptures zoomorphes du sud Brésilien et de l'Uruguai. Cahiers, Paris, 5, 175 p. (resenha por BECQUELIN P. L'Homme, Paris, 19(2): 103-104).

1992 A Arqueologia Brasileira. Brasília, Ed. Universidade de Brasília, 605 p., il.

ROOSEVELT, A.; IMAZIO, M.; MARANCA, S.

1991 Eighth millennium from a Prehistoric shell midden in the Brazilian Amazon. Science, 254 (5038): 1621-1624.

SALLES CUNHA, E.M.

1965b Sambaquis do litoral carioca. Revista Brasileira de Geografia, Rio de Janeiro, 1(27): 1-69.

SCATAMACCHIA, M.C.M.

1981 Tentativa de Caracterização da tradição Tupiguarani. Dissertação de Mestrado, FFLCH/ USP, São Paulo.

SCHELL, R.; YBERT, J.P.; GASPAR. M.D.

prelo Antracologia, uma nova fonte de informações para a arqueologia moderna. Revista Ciência Hoje. Sociedade Brasileira para o Progresso da Ciência.

SCHMITZ, P.I.; WÜST, I; COPE, S.M.; THIES, U.M.E.

1982 Arqueologia no centro-sul de Góias. Pesquisas, Instituto Anchietano de Pesquisas, RS, 33. 280p.

TENÓRIO, M.C.

1991 Pesquisas arqueológicas na Ilha Grande, Rio de Janeiro: o sítio Ilhote do Leste. Reunião da Sociedade de Arqueologia Brasileira, VI, Rio de Janeiro. Resumos.

1995 Sítio Illhote do Leste. Reconstituição de Distribuição Espacial. Escavaçōes de 1995. Reunião Científica da Sociedade de Arqueologia Brasileira, VIII, Porto Alegre. Resumos: 34-35. 


\section{TURNER, C.G.; MACHADO, L.C.}

1981 Um novo padrão de desgaste dentário e evidência de alto consumo de carbohidratos numa população esqueletal arcaica do Brasil. Reunião Cientifica da Sociedade de Arqueologia BrasiUCHÔA, D. leira, I, Rio de Janeiro: 201-206.

1978/ Sinópse do "Arcaico" do litoral de São Paulo. 79/80 P.I. Schmitz; A.S. Barbosa; M.B. Ribeiro (Eds.)
Temas de Arqueologia Brasileira 3. Anuário de Divulgação Científica. Instituto Gôianio de PréHistória e Antropologia, Universidade Católica de Góias, Gôiania, 7: 15-32.

WILLEY, G.; PHILLIPS, P.

1962 Method and theory in American Archaeology. Chicago, The University of Chicago Press.

Recebido para publicação em 20 de setembro de 1996. 